\title{
Estructura territorial, relaciones vecinales y gobierno de las comunidades en el norte de la Península Ibérica en la Edad del Hierro
}

\section{Cultural Landscape, Neighbourhood Relationships and Political Structu- re of the Ethnic Groups in North of Spain Iron Age}

\author{
Jesús F. TORRES-MARTíneZ ${ }^{1}$ \\ Departamento de Prehistoria, Universidad Complutense de Madrid, \\ Avda. Profesor Aranguren S/N, 28040.- Madrid \\ ketxutorres@yahoo.com
}

Recibido: 27-07-2012

Aceptado: 06-06-2013

\begin{abstract}
RESUMeN
Las relaciones vecinales son una de las variantes más importantes de las relaciones de solidaridad y reciprocidad en las sociedades humanas. Resultan esenciales para comprender fenómenos tan importantes como la construcción del territorio o la estructura social y política de los grupos humanos. A través de la Etnoarqueología es posible establecer modelos de este tipo de relaciones aplicables para la Edad del Hierro y emplearlos para explicar la evolución sociopolítica de las sociedades cantábricas en ese periodo en los distintos territorios de este marco geográfico.
\end{abstract}

Palabras Clave: Edad del Hierro, Cantábrico, territorio, relaciones vecinales, Arqueología, Etnoarqueología.

\begin{abstract}
Neighborhood relationships are one of the most important variables of solidarity and reciprocity relationships in human societies. They are essential to understand phenomena as significant as the construction of territory, or social and political structure of human groups. Through Ethnoarchaeology, it is possible to establish models of this kind of relationships, applicable to Iron Age, and to use them to explain sociopolitical evolution in north of Spain societies of this period, in every territory of this geographical framework.
\end{abstract}

KEY wORDs: Iron Age, North of Spain, territory, neighborhood relationship, Archaeology, Ethnoarchaeology.

\footnotetext{
${ }^{1}$ Investigador contratado Proyecto Forma Hispaniae Prerromanae. Ref. HAR2010-21650 (Subprograma HIST). Proyecto "Monte Bernorio en su Entorno". Instituto Monte Bernorio de Estudios de la Antigüedad del Cantábrico (IMBEAC). http://ucm.academia.edu/JesusFranciscoKechuTorresMartínez
} 


\section{Estructura territorial y relaciones sociales}

En este trabajo vamos a desarrollar un estudio sobre la estructura territorial y las formas de relación y de estructuración política de los grupos humanos en el Norte de la Península Ibérica en la Edad del Hierro. Debemos adelantar que una parte importante de las relaciones sociales y políticas que se establecen en este momento histórico se desarrollan a partir de las relaciones vecinales, por lo que dedicaremos una especial dedicación a este tipo de fenómeno, principalmente en lo que se refiere al ámbito del norte de la Península Ibérica, aunque este análisis puede servir también, por extensión, a un gran parte del ámbito de lo que se denomina Europa Céltica.

He empleado de modo genérico el término "norte de la Península Ibérica" entendiendo que pertenecen a este ámbito los territorios que van desde Galicia hasta Navarra (ambos incluidos) y el piedemonte de la Submeseta norte y valle medio del Ebro. Esta amplia adscripción se produce por cuestiones geográficas de muy diverso tipo, desde el relieve a otras de tipo climático-ambiental, ecológica, etc. en una escala Macro de análisis (Dincauze 2000: 198-201 y Tabla 9.1). Esta delimitación ya ha sido utilizada en otras ocasiones: J. Caro Baroja $(1940,1970,1977)$ empleó el término "el norte" como elemento geográfico delimitador varias veces en sus obras sobre los pueblos del cantábrico ("pueblos del norte") en el final de la Edad del Hierro. Otros autores lo identifican con el ámbito atlántico de la Península Ibérica, también con un claro contenido geográfico-ambiental (Murcia 1980; Almagro-Gorbea 2002; TorresMartínez 2003: 33-46; 2011: 21-30).

Sobre las relaciones vecinales, podemos definir este concepto como una forma de relación basada en la reciprocidad entre los habitantes de un área o región no sometidos a lazos de parentesco (relación familiar o de tipo gentilicio). Los que habitan una región y no están unidos por lazos de parentesco son vecinos y entre ellos no hay relaciones de tipo familiar sino vecinales, que son de tipo suprafamiliares o no-familiares. La red de relaciones vecinales, que permite el funcionamiento de esa sociedad en ese territorio, su explotación económica, administración y gobierno, son las estructuras vecinales o también instituciones vecinales. Dentro del ámbito de la familia y la parentela, las relaciones están basadas en el afecto y la reciprocidad de tipo familiar. Son más intensas cuanto más próximo es el parentesco. Pero fuera del ámbito de la familia las relaciones están basadas en una reciprocidad que es más intensa con aquellos que viven en una mayor proximidad o con los que se establecen lazos de vecindad y de amistad (a través del afecto).

Las relaciones de tipo vecinal han existido desde el comienzo de la humanidad cobrando especial importancia a partir del surgimiento del sedentarismo, para intensificarse con el desarrollo de las sociedades de tipo Protourbanas, en la Prehistoria Final. Es por tanto en la Edad del Bronce y en la Edad del Hierro (con más intensidad), cuando este tipo de relaciones y de instituciones alcanzarán pleno desarrollo y mayor complejidad en las sociedades que ahora nos interesan. Por este motivo, la detección de este tipo de formas de relación está íntimamente conectada con las cuestiones de poblamiento y de jerarquización territorial.

En uno de sus trabajos, Almagro-Gorbea (1999a: 41-42) propone, para la Edad del Hierro peninsular, un modelo de ocupación del territorio (y del nivel de desarrollo sociopolítico) a partir del tamaño de los núcleos. Modelo que desarrolló también para el caso especifico del norte de la Península Ibérica (Almagro-Gorbea 2002: 50-57). A partir de esta propuesta, un poblamiento con núcleos de mayor extensión media indicaría, a priori, una mayor jerarquización territorial y una mayor complejidad sociopolítica. Un poblamiento con núcleos de menor extensión media indica una menor jerarquización territorial y una menor complejidad sociopolítica. Los núcleos de mayor tamaño se considera que tendrían en principio una mayor importancia territorial, social y política. Esta clasificación debe ser considerada de modo relativo, ya que deben tenerse siempre en cuenta los tamaños medios de los núcleos existentes en cada área (Almagro-Gorbea1999a: 41-42, 2002: 50-57). A partir de esta propuesta inicial recientemente he propuesto una clasificación de los distintos tipos de núcleos y sus características para el final de la Edad del Hierro en el norte Peninsular (TorresMartínez 2011: 274-80):

- Oppida: Son los recintos con proyección estratégica de control del territorio y de las vías de comunicación naturales. Poseen un mayor tamaño relativo. Su estructura vecinal es compleja, con numerosas familias vecinas y funcionan como núcleos de representación del poder político. Son también lugar de depósito de reservas estratégicas colectivas. Su extensión se sitúa entre las 10 y las 20 Ha. e incluso más. Son los menos numerosos.

- Castros grandes: Son los recintos con una menor proyección estratégica de control del territorio y de las vías de comunicación naturales. Poseen un menor tamaño relativo con respecto a los oppida, pero mayor proyección sobre el territorio económico. Su estructura vecinal es compleja, con muchas familias vecinas. Son también lugar 
de depósito de reservas estratégicas colectivas. $\mathrm{Su}$ extensión media se sitúa entre las 5 y las $10 \mathrm{Ha}$. Son relativamente abundantes.

- Castros pequeños: Son los recintos en los que prima el aprovechamiento de los recursos económicos frente a una muy pequeña proyección estratégica sobre el territorio y las vías de comunicación. Su estructura vecinal es simple, con algunas familias vecinas. Son lugar de depósito de reservas locales a pequeña escala territorial. Su extensión media se sitúa entre las 2 y las $4 \mathrm{Ha}$. Probablemente son los más abundantes.

- Aldeas y Granjas: recintos dedicados al aprovechamiento de los recursos económicos. Estructura familiar o de varias familias vecinas. Reservas locales de tipo familiar. Su extensión media se sitúa entre 0,2 y $2 \mathrm{Ha}$. Son aparentemente los menos abundantes y probablemente los menos conocidos.

Las poblaciones más grandes, mejor defendidas y con mayor proyección estratégico-territorial son los oppida, seguidos de los castros de gran tamaño y de los castros de pequeño tamaño y aldeas y granjas. El surgimiento de estos grandes núcleos tiene lugar a partir del siglo III a. C. cuando algunos castros comienzan a desarrollarse hasta convertirse en oppida. Estos grandes núcleos probablemente ya funcionaban, o se convirtieron, en centros jerarquizadores de la ordenación territorial donde se concentraban determinadas funciones político-administrativas e incluso religiosas (A1magro-Gorbea 1999a: 36-37, 42, 39-42, 2002: 5457). La mayoría de los yacimientos de la Edad del Hierro conocidos en el Cantábrico se sitúan dentro de la definición de castros pequeños y de aldeas y granjas. Como hemos visto, este tipo de núcleos posee una mayor proyección económica sobre el territorio pero una relativa menor importancia socio-política (Gil Zubillaga y Filloy 1986; Gil Zubillaga 1993, 1995 Almagro-Gorbea 2002: 50-57; Torres-Martínez 2005: 315-17; 2011: 275-84).

Sin embargo, en este desarrollo es necesario introducir una variable más para poder comprender realmente los mecanismos de jerarquización y de funcionamiento socio-político de estas sociedades. Se trata del modelo de poblamiento que implanta la ocupación humana sobre los distintos territorios y que obedece básicamente a dos tipos: el poblamiento de tendencia dispersa y el poblamiento de tendencia concentrada.

El poblamiento de tendencia dispersa consiste en que en un determinado territorio existe una gran cantidad de núcleos de pequeño tamaño dispersos por el espacio disponible (valle, comarca, etc). El poblamiento de tendencia concentrada supone lo contrario: el poblamiento se concentra en un solo núcleo, con amplios espacios sin ocupación o con una muy baja ocupación. Es necesario distinguir entre patrón de poblamiento y número de núcleos por valle o comarca. Una ocupación densa de un territorio en forma de muchos pequeños núcleos separados tan solo por dos o tres kilómetros es un patrón disperso. En este tipo de cuestiones es de enorme importancia el factor geográfico-ambiental, que suele condicionar de modo decisivo la capacidad humana de establecer uno u otro modelo de poblamiento.

\section{Modelos territoriales de la Edad del Hierro en el Cantábrico}

En las últimas décadas, en lo que se refiere a la Arqueología del norte de la Península Ibérica, han destacado algunas aportaciones importantes de las que merece destacar sólo algunas. Para comenzar, la obra de A. Llanos y sus numerosas síntesis sobre la zona del país Vasco y Navarra y en general sobre el Cantábrico oriental (Llanos 1990a, 1990b, 1992, 1995, 1997) además de su numerosas publicaciones sobre distintos temas de esta misma área y sobre el emblemático yacimiento de La Hoya (Laguardía, Álava) y sus materiales. También son muy importantes las obras de X. Peñalver sobre el País Vasco (Peñalver 2001a, 2001b; Peñalver y San José 2003, 2011). Además, son de obligada referencia sobre Navarra las obras de A. Castiella (1977, 1993, 1995a, 1995b, 1999, 2004), tanto en solitario como junto a otros autores (Castiella et al. 1999a, 1999b), y más recientemente las de Armendáriz Martija (2008, 2009), o la obra colectiva recientemente aparecida de síntesis sobre todo el área oriental del Cantábrico (Llanos et al. 2009).

Tampoco se debe olvidar la producción sobre el centro del Cantábrico, área sobre la que se ha publicado una monografía a cargo de E. Peralta (2003) y más recientemente otra obra monográfica (Serna, Martínez y Fernández 2010) con un extenso catálogo sobre el poblamiento de la Edad del Hierro en esta área. Para Asturias hay que destacar el trabajo de J. M. González y Fernández Vallés (1966, 1976, 1978). También hay que mencionar la monografía sobre el ámbito castreño asturiano en el contexto del cantábrico central (de Blas, y Villa Valdés 2002) y la producción de autores como J. L. Maya González (1983, 1984, 1988, 2000), J. Camino (1995, 2002, 2003, Camino et al. 1997, Camino y Viniegra 1999; Camino, Estrada y Viniegra 2005), así como la de A. Villa Valdés (2000, 2002a, 2002b, 2007) o A. Fanjul (Fanjul 2005, Fanjul y Menéndez 2004). También son importantes las aportaciones que han supues- 


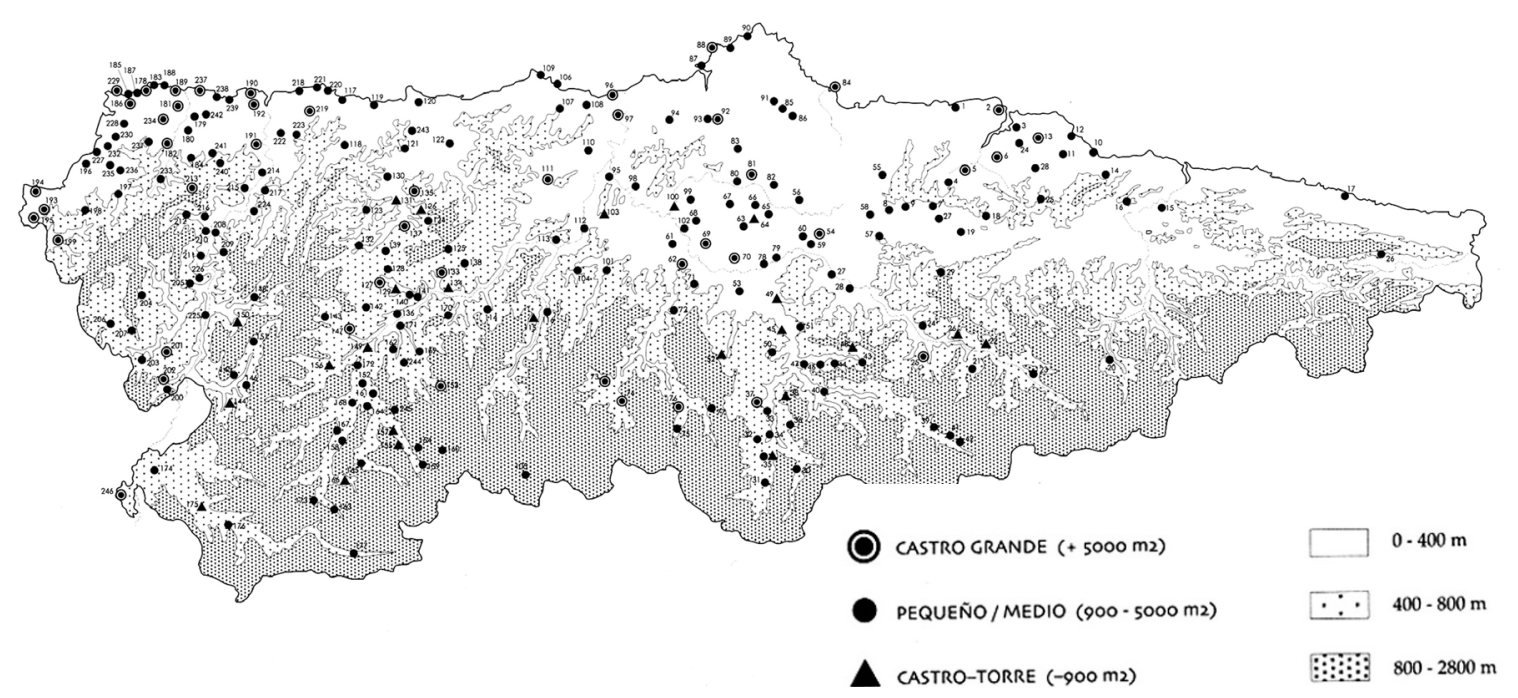

Figura 1.- Castros de Asturias según A. Fanjul (2005: 35).

to las monografías sobre el Castro de Campa Torres (Gijón, Asturias) (Maya y Cuesta 2001), el castro de Chao San Martín (Grandas de Salime, Asturias) (Villa 2007) o Llagú (Latores, Oviedo) (Berrocal-Rangel, Martínez. y Ruiz 2002). Para el área galaica son importantes las aportaciones de A. González Ruibal (2007) y los trabajos de C. Parcero $(2000,2002)$. Por último, recientemente se ha publicado una obra de conjunto sobre todo el norte de la Península Ibérica en la Edad del Hierro (Torres-Martínez 2011). Además de estas obras de referencia disponemos de una bibliografía extensa sobre distintos yacimientos y áreas que vamos a manejar a continuación.

Los distintos trabajos de recopilación de información arqueológica sobre esta extensa área geográfica permiten establecer, para la Edad del Hierro, unos patrones generales de ocupación del espacio bastante similares en casi todas las áreas. Podemos adelantar que, de un modo general, las pautas de ocupación territorial resultan bastante similares a las que perviven en la actualidad en muchas áreas. Estas coincidencias vienen condicionadas, principalmente, por el entorno geográfico-ambiental y también por el modelo económico de explotación agro-ganadera y forestal. Este modelo económico, aunque ha cambiado a lo largo de la Historia en algunos de sus elementos, ha mantenido hasta hace muy poco sus características esenciales. De este modo los patrones generales de ocupación del territorio que se dan en la Protohistoria final dibujan ya las áreas de ocupación de modelo disperso y concentrado que se constatan actualmente. Hay que señalar que el modelo perdura con pocos cambios desde la Protohistoria ya que los condicionantes geográfico-ambientales no han variado sustancialmente, ni tampoco el patrón básico de explotación del medio.

Vaya por adelantado que las limitaciones en este tipo de estudios resultan evidentes, y pasará algún tiempo hasta que se pueda reunir un volumen de información arqueológica que permita un conocimiento suficiente de la territorialidad de la Edad del Hierro y de su evolución diacrónica. En primer lugar, es seguro que no conocemos todos los núcleos, especialmente en el caso de los más pequeños. Es posible reconstruir una pauta general de ocupación a través de la ubicación de los núcleos localizados, su distribución por el territorio y la extensión de éstos. Sin embargo una gran parte de la información proviene de núcleos prospectados pero no excavados, por lo que las cuestiones relativas a la cronología de la ocupación de los núcleos no son precisas. Esto hace que la información de partida esté sesgada y sea más fácil referirse a la Segunda que a la Primera Edad del Hierro. No obstante, los datos arqueológicos disponibles indican que, al menos en el Cantábrico oriental, el $80 \%$ de los espacios habitados presentan continuidad entre el Bronce Final y Primera Edad del Hierro. Entre la Primera y la Segunda Edad del Hierro la continuidad de ocupación se produce al menos en el $50 \%$ de los núcleos, y sólo el 10, $65 \%$ del total son nuevas fundaciones (Llanos 1992: 440; 1995: 294; Castiella 1993: 125; 1995a: 198-99; Armendáriz 2009: 319-22).

Con todo, creo que actualmente resulta posible establecer pautas generales, al menos en grandes áreas territoriales. No obstante, deberemos esperar a un desarrollo más amplio de la Arqueología de 
la Edad del Hierro en nuestro país para poder tener una mejor y más concreta información a escala micro, meso y macro territorial. Es evidente que actualmente ya no se pueden plantear únicamente campañas de excavación de castros, sino que es necesario investigar territorios.

- Área del Cantábrico Central: En el caso del piedemonte y la plataforma costera de Cantabria los castros presentan en ocasiones mayores dimensiones que los conocidos en el piedemonte y la plataforma costera asturiana o vasca. Con los datos actuales podemos señalar que se dan las dos tendencias de poblamiento concentrado (en los valles más amplios, principales vías de comunicación) y disperso en áreas accidentadas y valles colaterales (Serna, Martínez y Fernández 2010: 112586; Fernández, Martínez y Serna 2010: 610-15; Torres-Martínez 2010). En la costa asturiana los tamaños oscilan desde unos centenares de metros cuadrados hasta las 1,30 Ha. de Llagú (Latores, Oviedo, Asturias). La tendencia general es de poblamiento disperso excepto en algunos puntos del área costera (como en el entorno de Campa Torres en Gijón) y en otras áreas de valles amplios y bien comunicados (Camino 1995: 29-141, 175-79; Camino y Viniegra 1999; Berrocal, Martínez y Ruiz 2002; Valle y Serna 2003: 354-55; Torres-Martínez 2011: 268-72). En el interior, en el piedemonte leonés, los núcleos tienen una extensión media también pequeña, como es el caso de las 1,25 Ha. de La Corona (Corporales, León), y su modelo es de tendencia dispersa (Marcos 1987: 480-81; Celis 2002: 97-110; González Ruibal 2007: 347; TorresMartínez 2011: 268-72).

La máxima expresión del poblamiento concentrado (nuclear y polinuclear) es el modelo territorial con oppidum o con castro principal que encontramos en algunas áreas de la costa cantábrica y en el límite sur de este territorio, en la transición hacia la submeseta norte y el valle del Ebro. En la "frontera sur" del cantábrico central y en la zona meridional de León, Palencia y Burgos, los oppida son de gran tamaño (de más de $10 \mathrm{Ha}$. y muchos con más de 20 Ha. y aún mayores) y se erigen en cabezas de un territorio en el que también hay castros y aldeas o granjas de menor tamaño (Sacristán et al. 1995: 352-54, 361-67; Almagro-Gorbea 1999a: 41-42; Blasco 2001: 202-04, 206-10; Maya y Cuesta 2001: 36; Almagro-Gorbea 2002: 58; Camino 2002: 149-55; Berrocal-Rangel 2004b: 75-76, 81-82; Fanjul 2005: 46-49, 81; GonzálezRuibal 2007: 176-86, 309-10, 338-49; Torres-Martínez 2011: 266-72).

- Área del Cantábrico Occidental: En el área galaica, cuanto más al norte y al occidente más excepcionales resultan los núcleos con grandes dimensiones, el de mayor tamaño es el Castro de Elviña (Elviña, La Coruña) con $8 \mathrm{Ha}$. Por lo general los grandes núcleos se concentran en el área costera meridional, en el suroccidente, destacando Monte Mozinho (Peñafiel, Portugal) con 20 Ha., San Cibrán de Lás (San Amaro, Carballiño, Orense) con 9,5 Ha., Sanfíns (Paços de Ferreira, Portugal) 15 Ha. o Briteiros (São Salvador de Briteiros, Portugal) que tiene 20,5 Ha. Frente a estos resultan mucho más numerosos los castros de entre las 1,5 y 2 Ha., y que resultan "grandes" frente a un gran número de núcleos que no llegan a tener una hectárea de extensión (Carballo 1990: 166-80, 188-89; Almagro-Gorbea 2002: 58; Parcero 2002: 188-229; González-Ruibal 2007: 176-86, 309-10, 338-49).

- Área del Cantábrico Oriental: En el País Vasco el tamaño medio de los núcleos es en general reducido y los núcleos con grandes extensiones son verdaderas excepciones. De los recintos conocidos, 52 tienen menos de 4 Ha., sólo 20 tienen más de 4 Ha. y tan sólo 10 alcanzan o superan las 5 Ha. Los núcleos se ubican en zonas elevadas sobre el curso de los ríos a distancias regulares. En la mayor parte de los casos se hace patente la complementariedad territorial (económica y política) de los distintos núcleos. En este territorio encontraríamos áreas con poblamiento de tendencia al modelo disperso y otras de tendencia al modelo concentrado dependiendo del relieve de los valles y de las principales vías de comunicación. Son diferentes las áreas montañosas del centro con respecto a algunos valles costeros o en el sur áreas como la Llanada Alavesa (Llanos 1995: 298, 30012, 313; Peñalver 2001a: 65, 2001b: 33-48, $135-$ 36, 242-44; Peñalver y San José 2003: 74; TorresMartínez 2011: 68).

- Área Cantábrico-Pirenaica: En el territorio navarro los núcleos localizados tienen extensiones reducidas (los núcleos se sitúan entre $0,30 \mathrm{Ha}$. y 1,7 Ha. y la media para la Segunda Edad del Hierro es de entre 1 y 1,5 ha,). La jerarquización de los núcleos en el territorio se produce a partir de los que tienen mayor tamaño y que ocupan un emplazamiento más estratégico, y los de tamaño menor se sitúan en función de la explotación de los distintos recursos (Llanos 1990: 176; Ruiz-Zapatero 1995: 30-34). El tamaño de los castros a los que se atribuyen funciones de castros principales y oppida es, en general, menor que en otras áreas del norte de la Península Ibérica. Sólo en el caso de La Custodia (Viana, Navarra) se alcanzan con 12,5 Ha. El reducido tamaño de los castros es un fenómeno generalizado en otros territorios del valle del Ebro. En la Rioja sólo el núcleo de Cruña (Inestrillas, Aguilar del Rio Alhama, La Rioja) llega a las 
13,5 Ha., una de las superficies más grandes en ese territorio. Pero en general se puede establecer un modelo de poblamiento de tendencia concentrada. Para la montaña navarra el modelo de poblamiento tiene una marcada tendencia hacia el poblamiento de tipo disperso. Los investigadores plantean, para esta zona, que el papel desempeñado por los oppida en otras áreas lo desempeñen determinados espacios rituales y que en la Segunda Edad del Hierro se produzca, en algunos casos, la pervivencia de organizaciones político-territoriales sin núcleo urbano como lugar central o principal, lo que las evidencias indican que ocurría también en otras áreas del cantábrico (Castiella 1977, 1993; Llanos 1995: 298, 310-11, 315; Berrocal 2004b: 75-76; Armendáriz 2008: 239-47, 313-14, 2009: 319-27; Torres-Martínez 2011: 268, 374-77).

Como hemos podido ver, parece existir en principio una gran diversidad de tendencias en la ocupación territorial, pero podemos establecer dos grandes modelos: un poblamiento de tendencia dispersa con tendencia a la ocupación densa del territorio y un poblamiento de tendencia concentrada con una ocupación menos densa del territorio. Esto construye también dos modelos de evolución de la estructura territorial basada en una distinta ocupación del espacio. Como hemos visto, la tendencia a este tipo de poblamiento disperso resulta más marcada en amplias zonas de Galicia, Asturias, Cantabria o del Pirineo en ambas vertientes, navarra y aquitana. Sin embargo, en ambos casos, podemos hablar de un mismo modelo económico general, aunque con diferentes estrategias de adaptación al medio, que implica la explotación de todo el territorio disponible. En este sentido, resulta muy importante constatar la complementariedad existente (económica y también política) en la ocupación del territorio entre los núcleos de pequeño tamaño (las granjas y aldeas) y los castros de gran tamaño y los oppida allí donde éstos existen.

La jerarquización de los núcleos en los distintos territorios se produce a partir de los de mayor tamaño y con una mayor proyección estratégicoterritorial, mientras que los que tienen menor tamaño se distribuyen principalmente en función de la explotación de los distintos recursos (Llanos 1990: 176). La tendencia general es que el tamaño medio de los núcleos tiende a aumentar según se sitúan más hacia el sur y el este, en la frontera entre el piedemonte cantábrico y la submeseta norte hasta el ámbito del Ebro. Esta diferenciación en el poblamiento dibuja dos grandes modelos de articulación del territorio para el final de la Edad del Hierro.
Como hemos señalado, la máxima expresión del poblamiento concentrado (nuclear y polinuclear) con oppida lo encontramos en algunas áreas de la costa cantábrica y en el límite sur de este territorio, en la transición hacia la Submeseta norte. En estas áreas los oppida son de gran tamaño y jerarquizan los territorios ocupados por castros de mediano tamaño y también algunas aldeas o granjas. Este modelo concentrado resulta distinto del modelo territorial de la Submeseta norte en el final de la Edad del Hierro, compuesto por núcleos de gran tamaño separados por grandes distancias (Sacristán et al. 1995: 352-54, 361-67). Desde éstos se controlan territorios extensos que, en algunos casos, no parecen presentar ocupación alguna. Los núcleos tienen gran extensión (entre 5 Ha. y 10 Ha. y aún mayores) y se sitúan en las vegas fluviales (las vías de comunicación naturales) que son también los terrenos de mayor potencial agrícola. Además estarían otros núcleos de menor tamaño (aldeas y granjas), mal conocidos arqueológicamente, y grandes espacios en los que aparentemente no hay ocupación alguna.

En otros territorios el poblamiento presenta un modelo disperso, que en algunos casos es de alta densidad, basado en núcleos de pequeño tamaño. Este tipo de ocupación respondería al patrón de poblamiento disperso y ultradisperso. Es el caso de gran parte de la Cantabria y Asturias montañosa y costera o de Galicia y de una parte de la zona oriental cantábrica en la que también podemos incluir algunas zonas de la Aquitania meridional. En las áreas mejor conocidas los núcleos tienen un tamaño generalmente pequeño y se distribuyen por todo el territorio de una forma más o menos regular. A los de mayor tamaño se les atribuye un papel de núcleo principal, pero no llegan a desarrollarse como oppida (Almagro 1999a: 41-42; Blasco 2001: 202-04, 206-10; Maya y Cuesta 2001: 236; Almagro-Gorbea 2002: 58; Camino 2002: 149-55; Berrocal 2004b: 75-76, 81-82; Fanjul 2005: 46-49, 81; González-Ruibal 2007: 176-86, 309-10, 33849; Torres-Martínez 2011: 266-72).

Tras estos dos modelos territoriales y de poblamiento tendríamos dos tipos distintos de modelos de relación vecinal:

- En uno de ellos, con poblamiento disperso y ocupación densa del territorio, la estructura de relación vecinal sería menos activa, aunque no por eso menos importante; todo lo contrario. Las estructuras gentilicias (de relación familiar y de la parentela) conservarían un mayor protagonismo e importancia a la hora de articular las relaciones sociales. Éstos fueron, como veremos más adelante, los territorios donde mayor pervivencia pudieron tener las formas de organización tipo pagi. 
- En otro, con poblamiento concentrado y con una ocupación menos densa del territorio, la estructura de relación vecinal sería mucho más activa y las estructuras gentilicias tendrían menor importancia a la hora de articular las relaciones sociales. En este tipo de territorio fue, como veremos más adelante, donde se produjo (en la mayoría de los casos) el desarrollo de formas de organización tipo oppida/civitates.

Estos dos modelos de poblamiento (o de proyección territorial) y de relación vecinal suponen también dos modelos distintos de evolución sociopolítica. Esto es lo que veremos a continuación.

\section{Modelos etnoarqueológicos de relaciones vecinales}

Los condicionantes geográfico-ambientales (relieve montañoso, cuencas fluviales y los ecosistemas) forman conjuntos que sirven para definir y delimitar conjuntos geográficos a distintas escalas hasta formar lo que se denominado Comarcas y Regiones Naturales. En estos espacios naturales, formando en muchos casos Comarcas Naturales, se desarrollarán Comarcas Históricas que suponen una síntesis de la adaptación humana a un medio muy duro y riguroso y que exige una considerable especialización en los patrones de ocupación y explotación de los territorios en procesos de larga duración (Hernández Pacheco 1934; Dantín 1942; Murcia 1980: 180-89; Méndez y Molinero 1994: 19-39; Torres-Martínez 2011: 21-27).

Para poder comprender adecuadamente la territorialidad en la Edad del Hierro (y en cualquier otro momento de la Historia) es imprescindible tener un conocimiento adecuado y suficiente del funcionamiento económico de esas sociedades. Como ya hemos expuesto, esto debe incluir también la Paleobiogeografía, las condiciones geográfico-ambientales y los recursos naturales que pueden ser obtenidos y producidos en cada territorio (Torres-Martínez 2003, 2005, 2011: 21-252). Estos elementos definen el territorio económico que posee una estrecha vinculación con el concepto de comarca natural y en un sentido más extenso de región natural que hemos mencionado. La continuidad de los territorios de la Edad del Hierro a través de la Historia, en algunos casos, se detecta en determinadas comarcas históricas o en formas de administración territorial como obispados, arciprestazgos, concejos, partidos judiciales, etc. (Dantín 1942; Parcero 2002: 36-170, 185-87; 200-11; González-Ruibal 2007: 312-13; TorresMartínez 2011: 21-38, 65-260). A través de lo que la Arqueología nos permite conocer existe una evi- dente coincidencia en estos modos de ocupación del espacio en la Protohistoria y en época histórica (Gómez Pellón 2005).

Para época contemporánea, en el cantábrico central, tenemos dos tipos de patrones de ocupación territorial tradicionales que se dan también en otras áreas del Cantábrico incluida la zona más oriental hasta Navarra. Han sido estudiados desde la Antropología y la Etnografía y, a partir de estos estudios, se han podido establecer unas pautas de adaptación cultural y de relación social que nos pueden servir para establecer modelos aplicables a la Edad del Hierro:

- El modelo de poblamiento disperso y ultradisperso, que establece unos espacios con un hábitat en el que los núcleos de poblamiento son familiares y con muy poca población y se dispersan por amplios territorios. Es un paisaje de granjas (en algunos casos barrios) más menos distantes unas de otras en el que la ocupación del territorio puede llegar a ser, sin embargo, intensa. Las relaciones son esencialmente familiares y las relaciones vecinales son menos importantes aunque no inexistentes: de hecho tienen gran importancia. Habitualmente la solidaridad familiar y de la parentela es más intensa que la vecinal, en gran medida por la dispersión y separación del vecindario, especialmente en el modelo ultradisperso. Los escasos núcleos, que cumplen el papel de puntos centrales, tienen un papel importante en la administración y gobierno del territorio. Este tipo de modelo se da en amplias zonas de la zona costera cantábrica y en algunas áreas montañosas. Este paisaje tradicional coincide con el que la Arqueología establece para las mismas áreas y otras similares de pequeños castros (de tipo aldea o granja) dispersos ocupando los valles fluviales desde las medias laderas y pequeñas alturas (Rivas 1991a: 66, 72-75, 1991b: 140-208; Gómez Pellón 1994: 50-51, 2005: 896905; Torres-Martínez 2011: 266-72).

- El poblamiento concentrado (nuclear y polinuclear) se caracteriza por un tipo de hábitat en el que los núcleos de poblamiento son de mayor tamaño y obedecen a una estrategia de concentración del poblamiento en determinados espacios. Tiene dos variantes: el poblamiento nuclear establece grandes núcleos en los que se concentra una gran cantidad de población en un valle o territorio mientras que el poblamiento polinuclear se basa en núcleos de menor tamaño, aunque grandes, dispersos en un valle. El primer modelo coincide con el modelo actual de pueblos y el segundo con el modelo de barrios. La solidaridad vecinal es mucho más importante que la familiar y la de la parentela y las relaciones vecinales resultan mucho más intensas. También lo es la institucionalización del 
autogobierno, especialmente para explotación de aquellos recursos que exigen una planificación y explotación coordinada entre todos los habitantes. En los núcleos principales se establecen las sedes de la administración y gobierno del territorio (Rivas 1991a: 66, 72, 74-79, 1991b: 208-243; Gómez Pellón 1994: 50-51, 2005: 903-905; Torres-Martínez 2011: 266-272).

Las relaciones vecinales, denominadas también relaciones territoriales, se establecen en ambos tipos de poblamiento, y se plasman en lo que se denomina ayuda mutua (favores, asistencia) (Gómez Pellón 2005: 916). Las relaciones vecinales y las prácticas de ayuda mutua tienen como fin minimizar el riesgo del azar genealógico, ayudan a paliar los efectos de los desastres económicos producidos por adversidades climático-ambientales y reducir el efecto de las desigualdades entre las distintas familias. Pero ante todo buscan la relación con los no-familiares (relaciones suprafamiliares) ya que muchas de estas ayudas y colaboraciones no son estrictamente necesarias y se producen tan solo por

[...] la configuración de los grupos y en la búsqueda de la cohesión social (Gómez Pellón 2005: 918).

Estas relaciones incluyen también la mera compañía, la diversión en común y la comensalidad, e incumben por igual a hombres y mujeres, involucrando en muchas ocasiones a toda la familia. Con el paso del tiempo tejen entre las familias que la practican (los habitantes del territorio) una identidad común y una cohesión solida y muy arraigada (Fidalgo 1984; Gómez Pellón 2005: 916-25; Valdés y Lorenzi 2004).

Los tipos de relación vecinal que se desarrollan a través de la ayuda mutua se producen principalmente en las labores agrícolas y ganaderas, que son las que tienen una mayor importancia para la subsistencia de las familias y del grupo (como conjunto de familias). Hemos de recordar que la asistencia requiere siempre una reciprocidad simétrica en tiempo y forma, más cualitativa que cuantitativa, que consiga el reequilibrio social y en la que no es posible la defección: dar y asistir, lleva implícito recibir (Gómez Pellón 2005: 921-22). También en los casos de estos avateres es necesario asistir y socorrer a las familias que sufren los desastres por parte de los que quedan a salvo, ya que en caso similar todos esperan que ocurra lo mismo en reciprocidad. Por último está la colaboración que prestan los hombres de cada familia en las tareas comunitarias que incumben al grupo en lo que hoy denominaríamos "obras públicas" que incluyen los trabajos de construcción y manteni- miento de distintas infraestructuras y edificaciones comunales (Rivas 1991b: 212, 217; Homobono 1991: 89; Gómez Pellón 2005: 916-25).

Estos patrones de comportamiento tienen una parte de adaptación cultural, pero también se constatan patrones de comportamiento que son los mismos que desarrollan otros pueblos de diferentes lugares del planeta y de distintos niveles de desarrollo cultural, social y tecnológico (Dyson-Hudson y Alden 1983). Es precisamente en las zonas de montaña (de cualquier lugar del planeta) donde más importantes son las relaciones vecinales, en un entorno donde una gran parte de los recursos económicos (productos de recolección, forestales, pastizales, etc.) tienen una baja predictibilidad, aunque una distribución espacio-temporal muy favorable, y requieren una estrecha colaboración familiar y vecinal (Dyson-Hudson y Smith 1983: 157-60; Torres-Martínez 2011: 367-70). Como hemos visto, en las áreas de montaña se dan los dos modelos de poblamiento por igual, dependiendo de la geografía de cada espacio. En las áreas con poblamiento de tipo disperso sería donde las relaciones vecinales son menos intensas, especialmente desde el punto de vista institucional. Justo al contrario de las áreas con poblamiento de tipo concentrado, donde este tipo de relaciones tiene un enorme protagonismo y son cotidianas.

\section{Relaciones de reciprocidad y relaciones veci- nales en el estudio de la Protohistoria Final}

Las relaciones vecinales son una de las formas de relaciones de solidaridad y reciprocidad más importantes en las sociedades humanas. Este tipo de relaciones resultan esenciales para poder comprender como funcionan fenómenos tan importantes como la territorialidad o la estructura social y política de los grupos humanos. En principio, este tipo de formas de relación resultan difícilmente documentables a través del registro arqueológico. No obstante, la Etnoarqueología y la Etnohistoria (el estudio del registro antropológico y de los autores grecolatinos desde la Arqueología) permiten obtener información con la que resulta posible establecer modelos sobre el funcionamiento de este tipo de instituciones en la Edad del Hierro (TorresMartínez 2006; Torres-Martínez y Sagardoy 2006; Moya-Maleno, 2008 y 2013). El estudio de este tipo de relaciones puede servir para comprender fenómenos como la evolución sociopolítica de las sociedades cantábricas en ese periodo en los distintos territorios de este marco geográfico. Estos modelos pueden ser aplicables también a otras áreas de Europa. 
Es importante aclarar que cuando nos referimos a "relaciones vecinales" no se trata de relaciones que se establecen entre los castros, sino entre los habitantes de los castros: es evidente que los castros no se relacionan. Esto tiene una gran relevancia a la hora de entender adecuadamente la importancia que tienen las relaciones vecinales (que ocurren entre personas, no entre núcleos) y, de ahí, el enfoque del análisis antropológico (etnoarqueológico) que sirve para comprender mejor estas.

Las relaciones vecinales y las formas de relación a través del intercambio (de bienes o de servicios) en las sociedades premodernas, han sido una de las cuestiones clave en el estudio histórico de la Prehistoria y la Antigüedad. La creciente necesidad de elementos empíricos para desarrollar este tipo de discusión de un modo científico ha propiciado que una gran parte de los datos manejados procedan de la Antropología y la Etnología. La Antropología Económica se ha centrado en la investigación de lo económico en las sociedades humanas, pero este tipo de conocimiento resulta útil sólo en parte a la Historia y a la Arqueología (Moreno 2011: 145-156, 161-170). Algunas de estas informaciones suelen carecer de proyección diacrónica y provienen de sociedades muy alejadas geográfica, cultural y temporalmente de las culturas protohistóricas europeas. Pero cuando establecen comportamientos o valores similares en culturas distantes en el espacio y en el nivel de desarrollo sociocultural, poseen lo que se denomina un «valor sociológico general» (Mauss 1971: 223-24). En todo caso, resulta completamente actual y válido (en general) el empleo de este tipo de informaciones como un medio de aproximación y comprensión de los modos de comportamiento social y aun de los contenidos ideológicos y morales de las sociedades protohistóricas europeas (Verger 2009: 62, 72-74).

Sobre la reciprocidad como elemento esencial para la articulación de las relaciones sociales la obra de referencia sigue siendo el "Ensayo sobre el Don" de M. Mauss (Mauss 1971, 2010; Sahlins 1983: 167-02; Giobellina 2010; Moreno 2011: 113-24). Este trabajo, publicado en 1924, recoge el carácter universal de las relaciones de reciprocidad, así como las leyes que rigen en cuestiones tan fundamentales como la generosidad y el intercambio. Básicamente podemos decir que dar, recibir y devolver (reequilibrar, mantener el equilibrio) son las bases de la convivencia entre los integrantes de los grupos humanos. Posteriormente la obra de K. Polanyi (1987) sirvió para remarcar la gran diferencia cultural existente entre las sociedades premodernas o pre-capitalistas y las actuales, aunque en realidad esta diferencia ya había sido señalada
ESQUEMA DEL ÁMBITO DE RELACIONES FAMILIARES Y VECINALES

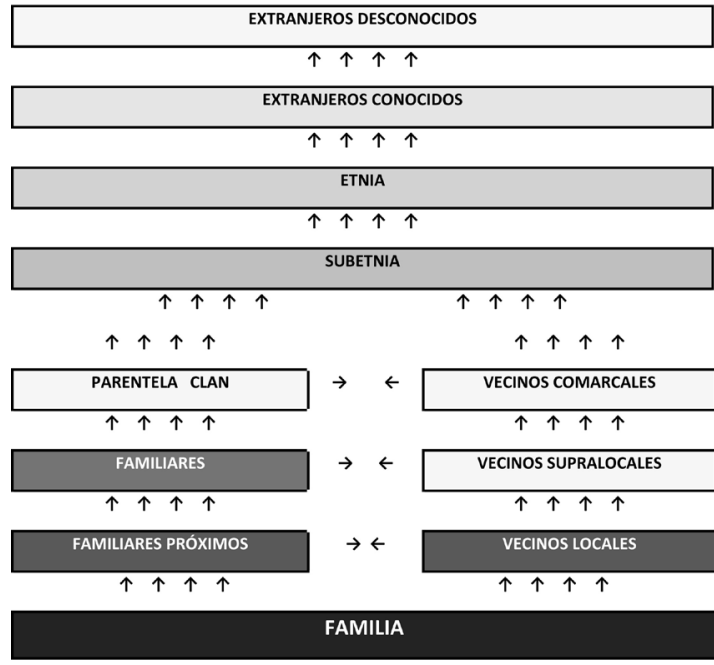

Figura 2.- Ámbito de relaciones familiares y vecinales en la Península Ibérica en la Protohistoria final (Esquema del Autor).

por M. Mauss. K. Polanyi señala que en las sociedades premodernas o pre-capitalistas los fenómenos económicos están imbricados de modo inseparable en el resto de las instituciones sociales. Todo lo social tiene una dimensión económica y todo lo económico tiene una dimensión social, lo que ya había explicado también M. Mauss (Moreno 2011: 124-34). Este concepto resulta muy importante para la comprensión de determinados fenómenos de larga duración histórica económico-culturales como la preservación, en las economías agro-ganaderas tradicionales de la sociedad contemporánea, de formas de relación (económicas) propias de momentos anteriores a la instalación del capitalismo y su sistema de valores.

La obra de M. Sahlins (1983) sobre Economía Prehistórica establece el carácter complejo y esencialmente cualitativo de lo económico en estas sociedades y señala la falta de sentido, en este tipo de estudios, de un enfoque individualista en un mundo de familias, linajes y grupos. También otros autores como M. Godelier (1999, 2000); M. Osteed (2002) y K. Sykes (2005) han aportado con sus trabajos elementos de discusión científica sobre este tema.

La reciprocidad se basa en la premisa de la generosidad. En estas formas de relación la generosidad es fundamental ya que, llegado el caso, los demás serán tan generosos con nosotros como nosotros lo hayamos sido con ellos. Por este motivo, la reciprocidad y la generosidad con los que convi- 


\section{RELACIONES DE RECIPROCIDAD EN LA EDAD DEL HIERRO} EN EL NORTE DE LA PENÍNSULA IBÉRICA

\begin{tabular}{|c|c|c|}
\hline TIPO DE RECIPROCIDAD & ÁMBITO DE RELACIÓN & ÁMBITO GEOGRÁFICO \\
\hline FAMILIAR & $\begin{array}{c}\text { FAMILIA, PARENTELA } \\
\text { ¿CLAN? }\end{array}$ & EXTENSIÓN VARIABLE \\
\hline VECINAL & VECINOS & $\begin{array}{c}\text { COMARCAL } \\
\text { SUPRACOMARCAL }\end{array}$ \\
\hline SUPRAVECINAL & ETNIA & $\begin{array}{c}\text { SUPRACOMARCAL } \\
\text { REGIONAL } \\
\text { SUPRAREGIONAL }\end{array}$ \\
\hline
\end{tabular}

Figura 3.- Distintos tipos y ámbitos básicos en las relaciones de reciprocidad en la Península Ibérica en la Protohistoria final (Esquema del Autor).

ven en proximidad resultan no solo obligadas, sino también (en gran medida) indiscriminadas. Se busca establecer, fortalecer y mantener amistades por medio de obsequios, favores y servicios. El regalo o Don se convierte en una inversión dentro de un fondo infinito de deudas entre individuos, familias y linajes. Las deudas de gratitud establecen una tupida y extensa red de relación en la que todo el mundo es deudor. Y no siempre esa deuda es posible compensarla (restablecer el equilibrio o reequilibrar) en el plazo de la vida del que la contrajo, quedando su obligación como un patrimonio de la familia, del linaje o del grupo al que pertenece. Las relaciones de reciprocidad son esenciales para comprender el desarrollo de las relaciones vecinales. La reciprocidad construye, en un determinado territorio, una comunidad con sus propias normas e intereses comunes. Esas relaciones establecen quién está dentro de ese sistema de relación e intercambio y quién está fuera, quién es el extraño, el otro.

En realidad no son sólo los regalos los que sirven para establecen redes de relaciones de reciprocidad: más importantes resultan los servicios que se prestan. Los favores o ayudas que se prestan e intercambian entre vecinos resultan apoyos de difícil cuantificación pero que en muchos casos resultan imprescindibles para la supervivencia de la familia o el grupo. Estas ayudas requieren de una devolución equivalente que restablezca el equilibrio entre las familias o los grupos. Así se establecen relaciones de reciprocidad básicamente de dos tipos: de servicios por servicios y de servicios por bienes. Este tipo de dinámica es la que ha pervivido en las relaciones de reciprocidad que se han mantenido en la sociedad campesina tradicional, al menos en el área cantábrica, como hemos podido recoger en la bibliografía etnográfica (Cabal 1992: 15-17; Fernández Benítez et al. 2002: 15; Valdés y Lorenzi 2004; Gómez Pellón 2005; Torres-Martínez 2011: 15-17, 254-56; Moya-Maleno, 2013: 176-189) y también en el trabajo de campo etnoarqueológico realizado personalmente.

Las relaciones de solidaridad y reciprocidad han sido esenciales para garantizar la cohesión y la supervivencia de los grupos humanos en las sociedades de tecnologías simples, en las sociedades protohistóricas y en las sociedades de la Antigüedad. Esta importancia se ha mantenido en toda Europa hasta época contemporánea, especialmente en la sociedad campesina tradicional y muy especialmente en los habitantes de las regiones montañosas como el Cantábrico (Fidalgo 1984; Valdés 2004; Gómez Pellón 1994; 2005: 919). Esto se debe a que en las duras condiciones del medio montañoso la vida de los grupos humanos no ha sido posible a medio o largo plazo sin la estrecha colaboración de todos aquellos que viven juntos o próximos, tanto entre los que son familiares o comparten una misma parentela (relaciones gentilicias) o entre los que son vecinos (relaciones suprafamiliares o vecinales). Pero estas dos formas básicas de relación han sido constatadas por la Antropología en sociedades muy distantes tanto desde el punto de vista geográfico como desde el del desarrollo tecnológico: tienen carácter universal (Dyson-Hudson y Alden 1983: 261-11).

Los distintos tipos de relaciones de reciprocidad poseen tres ámbitos básicos de desarrollo: en el ámbito de las relaciones familiares-parentela 


\begin{tabular}{|c|c|c|c|}
\hline \multicolumn{4}{|c|}{$\begin{array}{c}\text { RELACIONES DE RECIPROCIDAD EN LA EDAD DEL HIERRO } \\
\text { EN EL NORTE DE LA PENÍNSULA IBÉRICA }\end{array}$} \\
\hline \multicolumn{3}{|c|}{ MODELO DE POBLAMIENTO CONCENTRADO } \\
\hline TIPO DE RECIPROCIDAD & $\begin{array}{c}\text { ÁMBITO DE RELACIÓN } \\
\text { PREFRENTE }\end{array}$ & TIPO DE RELACIÓN & ÁMBITO GEOGRÁFICO \\
\hline FAMILIAR & $\begin{array}{c}\text { FAMILIA, PARENTELA } \\
\text { ¿CLAN? }\end{array}$ & POCO INTENSA & EXTENSIÓN VARIABLE \\
\hline VECINAL & VECINOS & INTENSA & $\begin{array}{c}\text { COMARCAL } \\
\text { SUPRACOMARCAL }\end{array}$ \\
\hline SUPRAVECINAL & $\begin{array}{c}\text { PAGUS } \\
\text { CIVITAS }\end{array}$ & INSTITUCIONAL \\
INTENSA & $\begin{array}{c}\text { SUPRACOMARCAL } \\
\text { REGIONAL } \\
\text { SUPRAREGIONAL }\end{array}$ \\
\hline
\end{tabular}

Figura 4.- Distintos tipos y ámbitos básicos en las relaciones de reciprocidad en la Península Ibérica en la Protohistoria final en Territorios con tendencia al Modelo de Poblamiento Concentrado (Esquema del Autor).

(incluidos los antepasados) y en el ámbito de las relaciones vecinales. El tercer ámbito es de los extranjeros y desconocidos (en el que podemos incluir a los enemigos). Un cuarto ámbito es el que incluye a los seres que habitan el Más Allá y los dioses.

Las relaciones de reciprocidad construyen las comunidades desde la misma base de las sociedades, ya que establecen complejas redes de interacción e interdependencia en mecanismos que se comportan como fenómenos de larga duración histórica. En estos sistemas de interdependencia todos deben favores y ayuda a todos de modo con- tinuo. Los servicios y los regalos se convierten en una garantía de ayuda y asistencia cuando sea necesario, especialmente en los momentos adversos. Por eso las redes de reciprocidad sobrepasan el espacio y el tiempo de los individuos. Además, se proyectan hacia otras esferas de relación como ocurre con los antepasados: las generaciones de un momento dado deben mucho de su bienestar a los que les precedieron en el tiempo y por su trabajo y sacrificio, en la paz y en la guerra, construyeron el territorio y garantizaron los recursos a sus descendientes. Por motivos similares, los mortales buscan tener buenas relaciones con los dioses ya

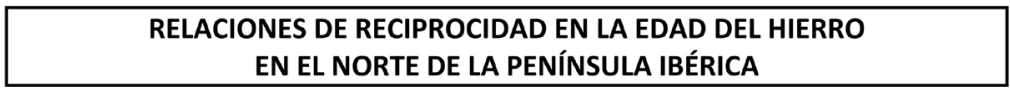

\begin{tabular}{|c|c|c|c|}
\hline \multicolumn{3}{|c|}{ MODELO DE POBLAMIENTO DISPERSO/ULTRADISPERSO } \\
\hline TIPO DE RECIPROCIDAD & $\begin{array}{c}\text { ÁMBITO DE RELACIÓN } \\
\text { PREFRENTE }\end{array}$ & TIPO DE RELACIÓN & ÁMBITO GEOGRÁFICO \\
\hline FAMILIAR & $\begin{array}{c}\text { FAMILIA, PARENTELA } \\
\text { ¿CLAN? }\end{array}$ & INTENSA & EXTENSIÓN VARIABLE \\
\hline VECINAL & VECINOS & $\begin{array}{c}\text { INTENSIDAD } \\
\text { VARIABLE }\end{array}$ & $\begin{array}{c}\text { COMARCAL } \\
\text { SUPRACOMARCAL }\end{array}$ \\
\hline SUPRAVECINAL & $\begin{array}{c}\text { PAGUS } \\
\text { ETNIA }\end{array}$ & $\begin{array}{c}\text { INSTITUCIONAL } \\
\text { INTENSIDAD MEDIA }\end{array}$ & $\begin{array}{c}\text { SUPRACOMARCAL } \\
\text { SUPRAIONAL }\end{array}$ \\
\hline
\end{tabular}

Figura 5.- Distintos tipos y ámbitos básicos en las relaciones de reciprocidad en la Península Ibérica en la Protohistoria final en Territorios con tendencia al Modelo de poblamiento disperso y ultradisperso (Esquema del Autor). 


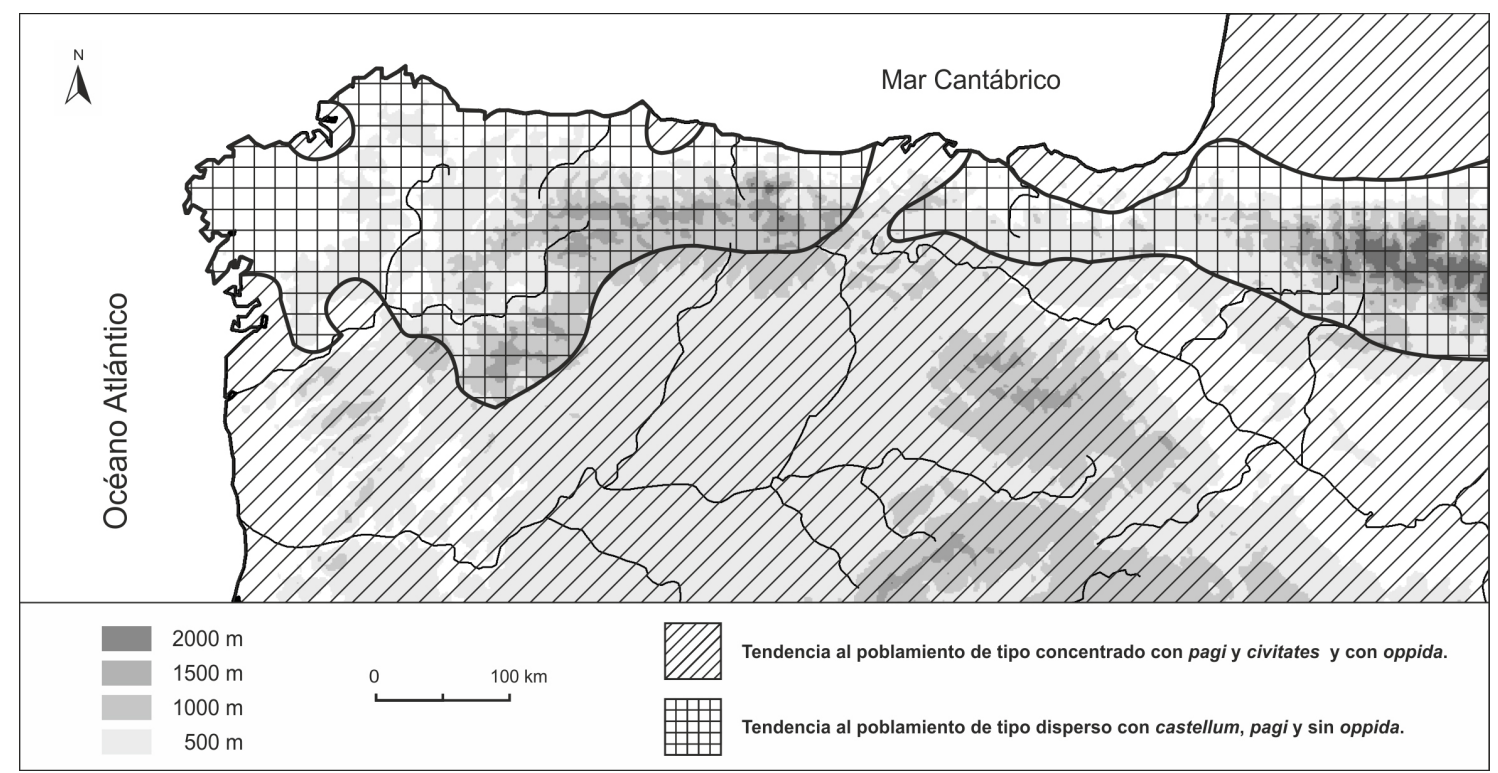

Figura 6.- Mapa con una propuesta de las zonas de dispersión de los principales modelos de poblamiento en el norte de la Península Ibérica en la Edad del Hierro. Con tendencia al "poblamiento concentrado", con el desarrollo de oppida y organizados en civitates. Con tendencia al "poblamiento disperso" con castros de mediano y pequeño tamaño organizados en Pagi. Mapa del autor y A. Martínez-Velasco.

que permiten la vida de los hombres a través de los dones de la naturaleza y de su voluntad. Ésta puede hacer que los humanos sean prósperos y felices, o pobres y desdichados. La generosidad debe llegar hasta los desconocidos y los extranjeros por medio de la hospitalidad. Ese mismo trato es el que se espera al viajar fuera del territorio.

Como ya hemos explicado, las relaciones vecinales están íntimamente unidas al territorio (territorialidad) en el que los humanos habitan y a sus condiciones medioambientales. Ambos factores condicionan las prácticas económicas ya que establecen los recursos disponibles, los recursos que pueden ser obtenidos y el modo en que éstos se pueden obtener. El relieve, los ecosistemas y el clima de un territorio son elementos esenciales en la construcción del territorio y de su explotación económica. La mayor parte de las prácticas de solidaridad y reciprocidad se producen en relación con la explotación de recursos básicos, aquellos que garantizan la supervivencia familiar. Esta asistencia incumbe en gran medida a la familia y a la parentela, pero en muchos casos intervienen los vecinos, incluso de forma más intensa que los familiares, simplemente por su mayor proximidad y por la inmediatez de la ayuda (Dyson-Hudson y Alden 1983). Las relaciones vecinales están relacionadas, en su mayor parte, con cuestiones que tiene que ver con la explotación de estos recursos, ya sea en la asistencia y ayuda mutua, o en la planificación y ordenación de los elementos que han de ser explotados en colaboración o mancomunadamente. Todas estas cuestiones incumben también a la creencia en la pertenencia a una etnia, a un mismo pueblo o grupo, incluso en casos de sociedades segmentarias, asentadas en territorios amplios y con modelos económicos diversos pero generalmente complementarios. Y también a la relación entre etnias diferentes en territorios próximos o incluso comunes (Barth 1976a: 13-, 23-24, 1976b: 153-61, 164-67, 170-72, Dyson-Hudson y Smith 1983: 151-60). Sin embargo, pese a las relaciones existentes entre las relaciones vecinales y la territorialidad, esto no ha sido tomado en cuenta hasta ahora en lo que se refiere a su papel esencial en del desarrollo de la etnicidad (Barth 1976a; Fernández-Götz 2008, 2011a: 11-14). Desde nuestro punto de vista, resulta evidente que los que comparten territorio y recursos y se hallan unidos por las redes de reciprocidad y de relación vecinal desarrollan identidades comunes. A partir de esto podemos empezar a hablar de etnicidad.

\section{Las relaciones vecinales en la Edad del Hierro en el norte de la Peninsula Ibérica}

En este trabajo sobre sociedades e instituciones indígenas utilizamos los términos latinos "pagus/ civitas/populus" porque son denominaciones de 
consenso actualmente aceptadas y empleadas por la gran mayoría de los investigadores que trabajan sobre la Edad del Hierro en Europa. Se emplean de igual modo que otros términos latinos y griegos clásicos como "oppidum", "magistratei", "principes", "acrópolis", "necrópolis", "ustrinum", polis, etc. Estas denominaciones (pagus/civitas/populus) se empezaron a utilizar porque los autores grecolatinos empleaban dichos términos como aquellos que definían, de la forma más aproximada y cercana a su cultura, la realidad que estaban viendo directamente en los pueblos de Europa central y occidental. Por tanto estos términos no pertenecen a la categoría de "formas administrativas romanas" cuando son empleados de este modo y en este contexto. Son términos latinos, referidos a cuestiones de índole política y territorial pero no definen términos administrativos romanos, sino aquellos indígenas más similares a los romanos. Se trata, por tanto, de denominaciones con las que los autores grecolatinos describen las etnias, territorios e instituciones indígenas de la Península Ibérica (y de otras partes de Europa), y se emplean para caracterizar a estos pueblos. Las unidades administrativas romanas resultan distintas y tienen, en la mayoría de los casos, denominaciones diferentes (Muñiz 1994: 77-84; Solana 1993: 159-79; Burillo 2007: 252-54).

Hoy en día esto es conocido y comprendido por la abrumadora mayoría de los investigadores que aceptan dichos términos asumiendo, evidentemente, que describen realidades político-territoriales indígenas desde una mentalidad griega o latina, pero no unidades administrativas romanas. Para una buena contextualización de la terminología asociada a la "civitas" y la relación entre "oppidum" y "civitas" podemos señalar, como ejemplo, las explicaciones de J. Muñiz Coello (1994: 7784) al respecto del uso de este tipo de términos. También son claras las explicaciones de F. Buri1lo (2007: 252-54) y de J. D. Sacristán de Lama (Sacristán 2011: 206) sobre la "civitas" como institución indígena. Además, entre los investigadores nacionales que utilizan estos términos podemos mencionar también a L. C. San Miguel Maté (1995); M. V. García Quintela (2002). Más recientemente debemos destacar la aportación de M. Fernández Götz sobre este tema y los autores que sobre él se han pronunciado (Fernández Götz 2011: 10-12). Sobre el empleo de estos términos para el ámbito del Cantábrico y la realidad que están denominando también he desarrollado unas explicaciones extensas recientemente (TorresMartínez 2011: 265-383). Además el uso de estos términos se encuentra en la obra de un gran número especialistas de otros países de Europa. Es el caso de N. Roymans (1990), V. Kruta (2000), J.-L.Brunnaux (2008), S. James (2005) o S. Fichtl (1994, 2005, 2012a, 2012b) que es uno de los que más ha profundizado en el estudio de estas cuestiones. Pero también otros autores como J. Collis (2007), T. Moore (2011) o S. Verger (2009) han hecho importantes aportaciones. Por tanto esta terminología permite un uso de "consenso" de estos términos, que denominan fenómenos que están siendo cada vez mejor comprendidos y definidos por los investigadores. Una vez aclarado este extremo pasemos al estudio de las relaciones vecinales y las estructuras políticas.

Las sociedades célticas de la Edad del Hierro no pueden ser comprendidas sin entender la enorme importancia que tenían las prácticas de la solidaridad y reciprocidad. Este tipo de conductas son las que sirven para establecer y construir las redes de relaciones vecinales. Como hemos visto, a través de los estudios antropológicos y etnográficos es posible comprender cómo este tipo de relaciones (de tipo suprafamilar) establecen fuertes lazos de pertenencia al grupo y de cohesión social en amplios territorios. Son este tipo de relaciones las que permiten, en la Edad del Hierro, el desarrollo de formas de relación y gobierno como son los pagi $\mathrm{y}$ posteriormente las civitates $\mathrm{y}$, en un proceso más complejo, las etnias. Todo esto en sociedades agro-ganaderas, de ideología guerrera y de tendencia fragmentaria (Fig. 7).

Estos ámbitos de relación y de estructuración social y territorial debieron surgir con la ocupación de todo el territorio disponible y la aparición de núcleos protourbanos (aldeas y poblados). La explotación de territorios densamente ocupados requiere una ordenación estricta del acceso a los recursos ya que la competencia por éstos significa en la mayor parte de los casos su pérdida para todas las partes. Las relaciones vecinales establecen unas normas que permiten una convivencia pacífica y una explotación ordenada del medio y sus recursos, que en muchos casos ha de realizarse de modo conjunto y cooperativo entre grupos no siempre unidos por el parentesco. Este tipo de relaciones, perfectamente estructuradas y regladas por la tradición, se basan en la práctica de la reciprocidad entre vecinos.

Dentro de la estructura vecinal conviven, de forma estrecha, inseparable y complementaria, dos tipos de relación entre los habitantes de los distintos territorios: las relaciones gentilicias y la estructura vecinal. La estructura de relación gentilicia se establece a través de la pertenencia a la familia, a la parentela (consanguineidad real) o a otras formas de parentesco de carácter mítico (consanguineidad simbólica). La estructura de 


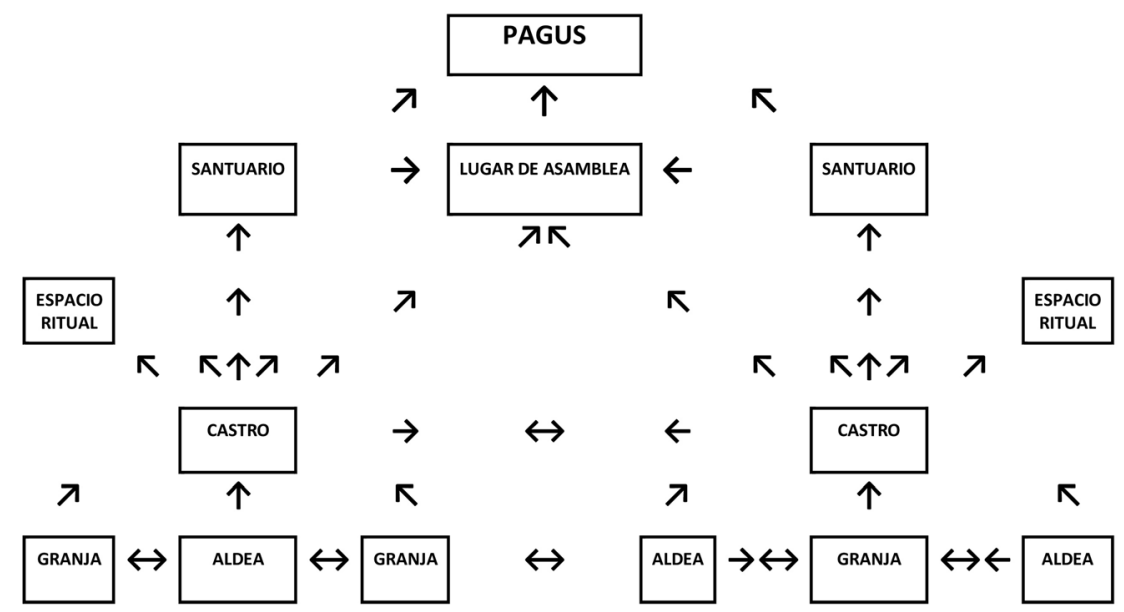

Figura 7.- Esquema con propuesta de funcionamiento de la estructura político-territorial de un pagus de la Edad del Hierro en el norte de la Península Ibérica. Modelo que sería el generalizado en la Primera Edad del Hierro y que se mantendría en algunas zonas en la Segunda Edad del Hierro (Esquema del Autor).

relación vecinal se establece a través de la pertenencia a un territorio que es explotado de forma conjunta con otras familias en redes amplias de planificación y colaboración solidaria (no competitiva) de explotación de los recursos. Ambos tipos de estructuras se organizan a partir del sexo y se ordenan por grupos de edad, y ambas cuentan con su propio sistema de reciprocidad. Además, estas dos estructuras forman el ámbito de relación social y político de estas sociedades que habían evolucionando progresivamente hasta formar lo que los autores grecolatinos percibieron y denominaron como ethnos/natio.

Este tipo de estructura territorial de relación económica y social intensificará su desarrollo y su institucionalización entre el final de la Edad del Bronce y la Primera Edad del Hierro, con la aparición de la sociedad campesina y guerrera de los castros, organizada muy probablemente a través de pagi. Su institución más característica era la asamblea, que representaba la culminación de la estructura de relaciones vecinales, donde las familias habitantes de un mismo territorio (o sus jefes o representantes) tomaban decisiones y celebraban cultos religiosos conjuntos. Estas sociedades pueden elegir jefes carismáticos (rex), en ocasiones dotados de un importante contenido religioso. Posteriormente esta sociedad evolucionará hacia la sociedad de los oppida/civitates/populi como elementos vertebradores de la estructura políti- co-territorial (Almagro-Gorbea 2002: 64; Brunaux 2004: 17-18). Este modelo, que explicaría el funcionamiento de las sociedades de la Edad del Hierro del norte de la Península Ibérica, resulta aplicable a otras sociedades del ámbito céltico del occidente de Europa y que otros autores describen con contenidos equivalentes (Fichtl 2004: 121-24; Verger 2009: 62-66; Torres-Martínez 2011: 35883; Fernández-Götz 2011a: 11-14) (Fig. 8).

El surgimiento de núcleos de gran tamaño y muy densamente habitados (castros grandes, oppi$d a$ ) hace emerger un nuevo modo de interacción ya que la mayoría de los habitantes ya no eran familia, parientes o parentela. Surgen así modos de relación que superaban ampliamente el ámbito gentilicio (de relaciones de parentesco real o ficticio): las formas de relación de tipo vecinal (el de las relaciones de tipo suprafamiliar). Este nuevo tipo de relaciones de complejidad creciente hace necesario la celebración de asambleas y otras formas de relación y coordinación de la vida colectiva. Este tipo de relaciones e instituciones vecinales debían existir ya en épocas anteriores, ya que servirían para coordinar y arbitrar cuestiones económicas, territoriales y sociopolíticas entre familias y linajes que viven separados en núcleos, hábitats $\mathrm{y}$ territorios diferentes.

Estas instituciones vecinales debieron comenzar a gestionar las reservas comunales y las relaciones económicas, sociales y políticas de las nu- 


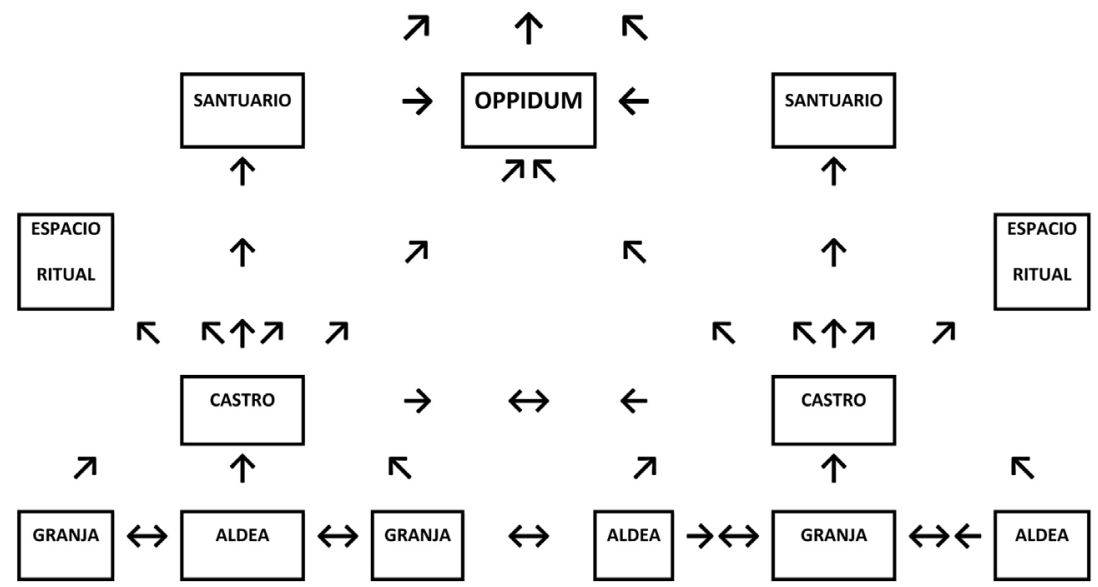

Figura 8.- Esquema con propuesta de funcionamiento de la estructura político-territorial de una Civitas articulada en torno a un oppidum. Modelo en expansión en la Segunda Edad del Hierro (Esquema del Autor).

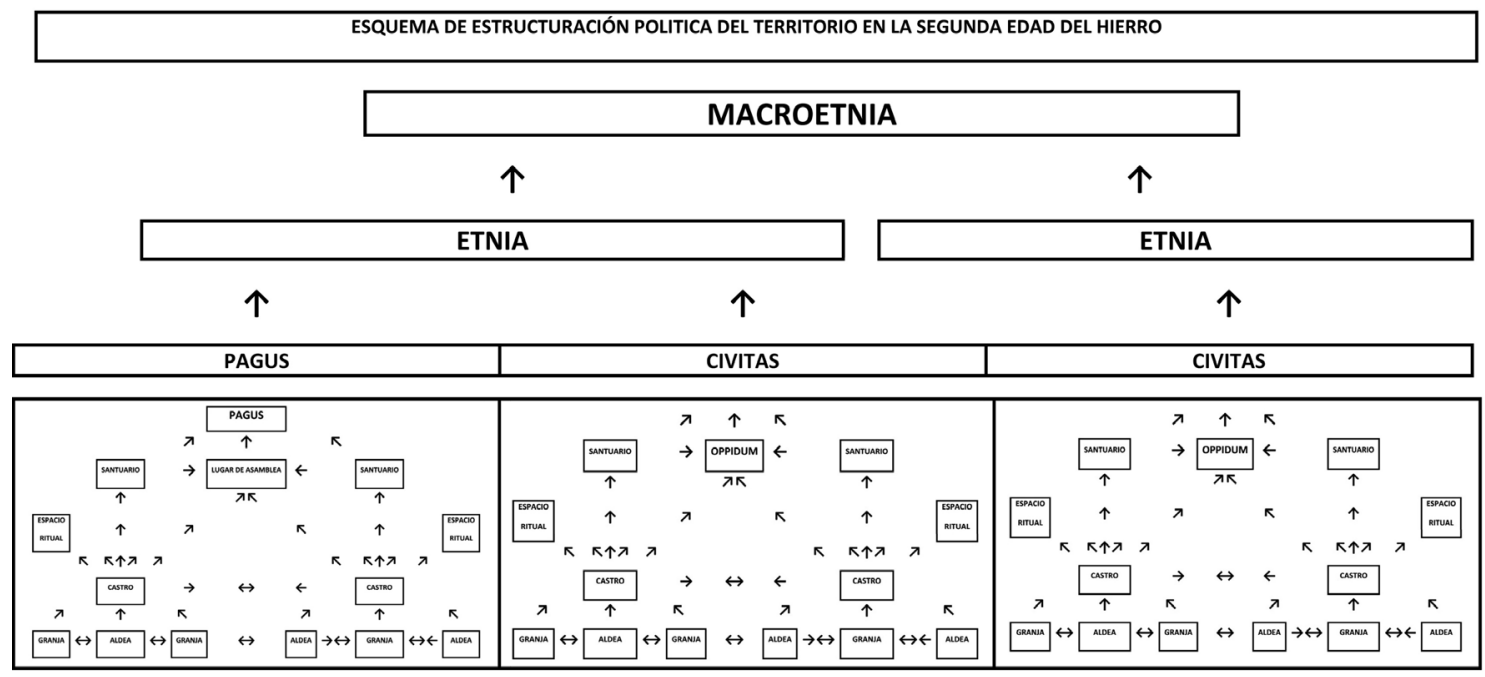

Figura 9.- Esquema con propuesta de articulación de la estructura político-territorial de las Etnias en el norte de la Península Ibérica en la Edad del Hierro. Modelo en expansión en la Segunda Edad del Hierro: Las cajas inferiores corresponden con la Figura 8. (Esquema del Autor).

merosas familias que viven juntas en un ámbito de estrecha cooperación y defensa y ayuda mutua. De este modo, se produciría el desarrollo decisivo del concepto de territorio y bienes comunales, y de los derechos que los habitantes de los distintos núcleos tienen sobre los recursos y los distintos espacios de los territorios comunes. Estos derechos se disfrutan por la pertenencia al grupo y se situa- rían por encima de los derechos que las distintas familias y linajes pudieran poseer. Esto supone un nuevo modo de entender el territorio que debió desarrollarse lentamente, y de forma cada vez más intensa, a lo largo del final de la Edad del Bronce y la Primera Edad del Hierro hasta desembocar en las estructuras que denominamos protourbanas de la Segunda Edad del Hierro. 
Dentro de esta evolución general, los pagi (unidades territoriales menores) no desaparecerán sustituidos por lo que los autores grecolatinos denominan civitas (unidades territoriales a escala de etnia), sino integrados dentro de ellos. Estos procesos de unión o absorción de pagi, y en algunos casos de sinecismo de distintos grupos en un oppidum/civitas, nos resultan aún demasiado desconocidos para poder ser descritos (González Ruibal 2007: 338-48; Torres-Martínez 2011: 27484). Probablemente no exista un único proceso o modelo, sino muchos diferentes según el área y el momento histórico. Sin embargo, como hemos visto, las condiciones geográfico-ambientales del espacio físico condicionan un tipo de ocupación del territorio que no propicia el surgimiento de la sociedad de los oppida en todas las áreas. Es lo que M. Almagro-Gorbea (2002: 58) denomina como "Zona III" dentro de su modelo de urbanismo de la "Hispania húmeda", y que comprende las zonas más occidentales del Cantábrico principalmente, aunque estas mismas características son compartidas por otras zonas de montaña del norte de la Península Ibérica, como ya hemos explicado anteriormente (Pereira 1982, 1983; Santos 1985; González Rodríguez 1986: 81-82, 113; Rodríguez Colmenero 2001; García-Quintela y Santos 2008: 52-59; Armendáriz 2008: 239-47, 313-14, 2009: 319-27).

En otras zonas de Europa los pagi mantienen también su vigencia en la Segunda Edad del Hierro, especialmente en las zonas montañosas donde es más frecuente un poblamiento de tipo disperso. En Helvetia este tipo de organización responde a un territorio en el que la ocupación se produce principalmente a través de aldeas (vici) dispersas por un territorio montañoso. Según sabemos a través de los textos de César B.G. (I, 5, 2 y I, 12, 4-6), el territorio de los helvetios se estructura a partir de cuatro pagi, doce oppida y cuatrocientas aldeas y granjas. Estos pagi serían instituciones de tipo vecinal que agrupan a los habitantes de un territorio, probablemente de una "comarca natural". En este caso los pagi, cuyo desarrollo sería anterior al surgimiento de los oppidum/civitas, aparecen plenamente vigentes (Jullian 1901: 79-87; GarcíaQuintela 2002: 74).

De este modo, al final de la Segunda Edad del Hierro convivían, en proximidad, dos tipos de poblamiento y de estructura de relación social y política. Las sociedades de tipo pagus, que mantendrían las estructuras políticas que para nosotros serían más propias de la Primera Edad del Hierro. $Y$ las que surgen en el periodo medio y final de la Edad del Hierro, definidas como de tipo protoestatal. Éstas se articulan a través de los oppida o de castros de mediano y gran tamaño (que cumplen similares funciones) dando lugar a lo que los autores grecolatinos denominan como civitates. Este último caso supone el máximo grado de desarrollo de lo que hemos definido como un modelo de estructura vecinal de sociedades campesinas y que, como hemos comentado, resulta diferente de los modelos urbanos del Mediterráneo.

En un nivel más básico de relación social y política (pero no por eso menos importante) se encuentra la administración de los territorios económicos. Éstos estaban formados por amplios espacios que se ocupaban de modo estable y continuo junto con otros que se ocupaban tan sólo estacionalmente o periódicamente, normalmente de forma compartida o mancomunada con otros grupos. La administración de los derechos de acceso y explotación de los territorios que se ocupan y explotan de modo continuo y estable estaría en manos de asambleas locales de vecinos, en las aldeas y castros pequeños o bien en centros religiosos en áreas de poblamiento disperso. Este tipo de estructuras habrían tenido una pervivencia histórica en un fenómeno de larga duración histórica que se constata hasta la Edad Media y, en algunos de sus elementos esenciales, hasta la actualidad (Almagro-Gorbea 1995: 443, 1999b: 4142; Asenjo y Galán 2001; Balbín 2005; Gómez Pellón 2005: 905-16; Torres-Martínez 2011: 367-70, 374-77). Estas asambleas (tanto las de tipo local, como las de un ámbito territorial de relación más extenso, de tipo pagi) debían estar coordinadas, a su vez, con otras asambleas vecinales de carácter más amplio y con competencias territoriales más extensas, que englobarían a las etnias. Sin embargo, la administración de los derechos de acceso y explotación de los territorios que se ocupan tan solo estacionalmente o periódicamente de forma compartida o mancomunada con otros grupos, requieren de asambleas en las que deben participar representantes de los distintos pagi e incluso de otras etnias.

La celebración de asambleas, con los rituales religiosos, los banquetes y las fiestas posee per se un gran significado y contenido como sistema de intercambio equilibrado de bienes dentro de los sistemas de reciprocidad de tipo familiar y de los de tipo vecinal, pero más marcadamente dentro de los de tipo vecinal. Es en estas ocasiones cuando se intercambian todo tipo de alimentos especiales, de tipo excepcional, y se emplean reservas de alimentos (fondos ceremoniales) para agasajar a los vecinos. También se intercambia información, se establecen pactos, se establecen matrimonios, etc. De este modo las asambleas eran momentos para la agregación social y el reforzamiento de la co- 


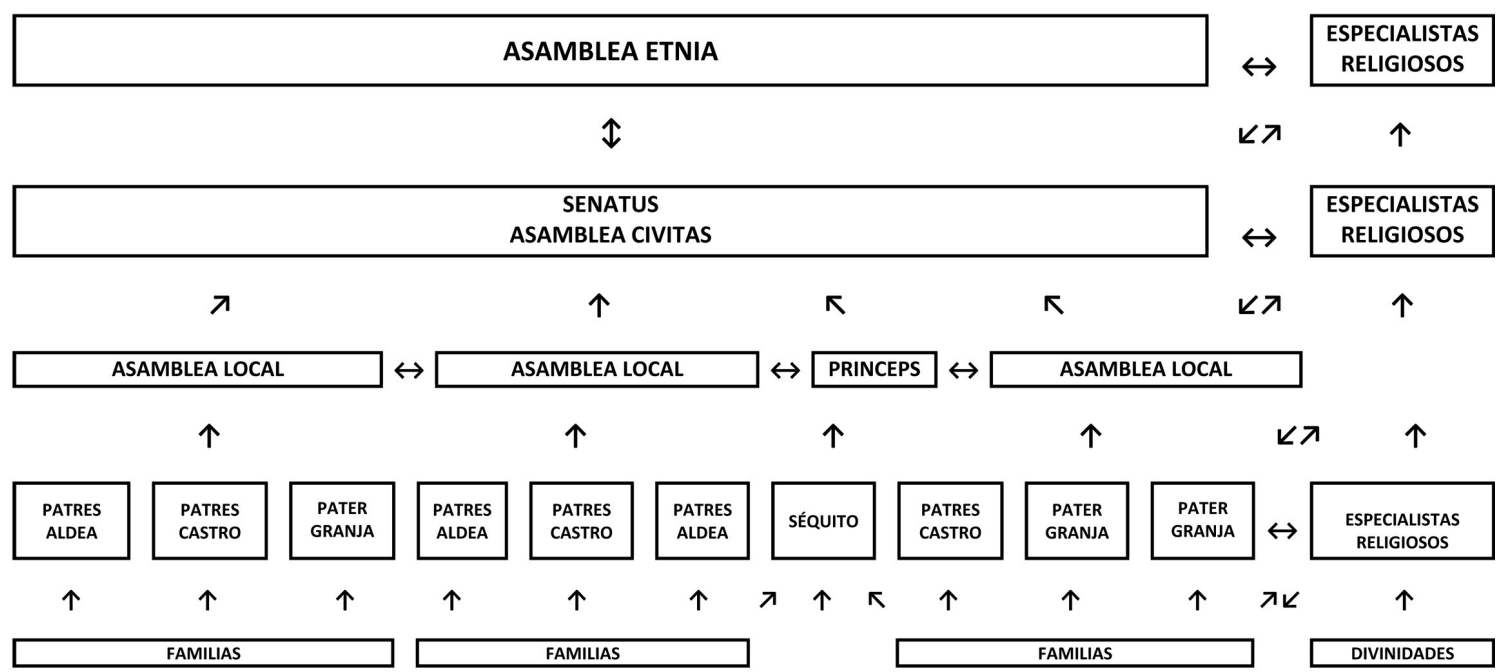

Figura 10.- Esquema con propuesta de articulación de la estructura política de una civitas (Segúnda Edad del Hierro) en el norte de la Península Ibérica en la Segunda Edad del Hierro (Esquema del Autor).

hesión de los grupos (Wolf 1975: 16-17; Sahlins 1983: 241; Berrocal-Rangel 2004a; Torres-Martínez 2011: 377-83, 480-81, 549-59).

Cada vez son más frecuentes los descubrimientos arqueológicos con evidencias sobre este tipo de prácticas en el interior de los núcleos (ÁlvarezSanchís 1993: 272-79; Marco 1993: 496; Ruiz-Zapatero y Álvarez-Sanchís 1999; San Miguel Maté 1995: 373-74; Berrocal-Rangel 1992: 199-201, 1994, 2004; Almagro-Gorbea y Berrocal 1997: 571-85; Torres-Martínez 2005: 318-19, 2011: 48087). Fuera de los núcleos estos espacios también se han identificado: el yacimiento de Gastiburu (Arrazua, Vizacaya) recientemente publicado por L. Valdés sería, precisamente, un lugar de culto y asamblea (Valdés 2006, 2009a, 2009b; Valdés y Pujana 2003).

Estrabón (III, 3, 7), al referirse a los pueblos del cantábrico describe una "asamblea", una celebración comunal en la que se desarrollan rituales religiosos, reuniones políticas y maniobras de tipo "militar". La celebración descrita probablemente comprendería a toda una etnia. Este tipo de celebraciones colectivas serían uno de los elementos fundamentales para el reforzamiento de los lazos de solidaridad del grupo y de reforzamiento de la identidad colectiva (Almagro-Gorbea 2002: 64; Brunaux 2004: 17-18; García Quintela et al. 2003; Gómez Espelosín 2007: 217, nota 39 y 219; Alberro 2006; García Quintela y Santos 2008: 128-31; Torres-Martínez 2011: 320-21, 377-78, 480-87). Este tipo de instituciones han sido tratadas tam- bién por otros autores europeos para otras áreas de Europa destacando los trabajos al respecto de S. Fichtl (2005: 145-49, 2012: 121-24), Ch. Peyre (1996: 6-8) o S. Verger (2009: 63-64) entre otros, mientras que una visión de conjunto sobre este tipo de instituciones ha sido publicada por M. Fernández-Götz (2011a: 12-14, 2011b).

Hemos de tener en cuenta que estas sociedades son segmentarias y están muy jerarquizadas (familiar y vecinalmente). Además, resulta evidente que, en muchos casos, existirían importantes desigualdades sociales. Estas contradicciones aparentes, en sistemas que poseen mecanismos de equilibrio precario, son en realidad propias de cualquier sociedad humana. Tanto los mecanismos de reciprocidad como los mecanismos de gobierno vecinal buscan establecer una relativa "igualdad de oportunidades" entre todos los integrantes de cada comunidad. Sin embargo esto no convierte en iguales a todas las partes, y determinados individuos, familias o linajes logran acumular amistades, influencia, prestigio, recursos económicos: poder, lo que les sitúa en la cúspide social.

Sin embargo, en este tipo de sociedades, estas situaciones suelen ser temporales e incluso meramente transitorias. El relevo de los líderes y las figuras carismáticas en las estructuras de poder debía ser continuo o, por lo menos, relativamente rápido. $\mathrm{Y}$ es que las cualidades personales, el talento y el carisma que permitían recibir el favor y la admiración de los demás (dentro de ese sistema de valores), recaían sucesivamente en distintos in- 
dividuos y grupos familiares. Pero, y esto es muy importante, la influencia y el poder conseguido establecen una deuda de servicio tanto para con aquellos que lo han hecho posible como con los que simplemente lo aceptan. Y es que la relevancia alcanzada nunca parece conseguir el consenso absoluto.

En un párrafo verdaderamente interesante, Cesar B.G. (VI, 11-2-5) explica cuál era la situación de la Galia en el momento de su conquista, situación que resulta probablemente extrapolable a una gran parte del ámbito céltico de Europa occidental

[...] En la Galia hay bandos, no sólo en todos los pueblos, distritos y comarcas, sino incluso, casi dentro de cada familia, y son líderes de estas facciones los que se considera que, a su entender, tienen más prestigio: todos los asuntos y decisiones se someten a su arbitrio y dictamen. Y esta costumbre parece existir desde antiguo con el propósito de que nadie de entre el pueblo se encuentre indefenso frente a un potentado, pues ninguno tolera que se avasalle o acorrale a los suyos y, si no procede así, pierde toda autoridad entre ellos (Caerols 2006; Verger 2009: 6274; Fernández-Götz 2011a: 14, 17-20).

En este tipo de relaciones, en la consecución del poder, resulta muy importante el prestigio, que está sujeto a los mecanismos de la reciprocidad y del reequilibrio continuo. Es este equilibrio en las relaciones vecinales lo que explica la cohesión interna de unas sociedades segmentarias y muy alejadas de la lógica social actual de Europa. Los sistemas de prestigio y la importancia del honor, que atañe a todos los individuos (no sólo a las élites y a los dirigentes) y que implica también a las familias, son las garantías de ese sistema en continuo reequilibrio. Dar implica recibir y volver a dar de nuevo, más en un sentido cualitativo, aunque lo cuantitativo fuera también importante, pero dentro de ese sistema moral de la deuda. Deuda que resulta imposible olvidar y en el que la demora innecesaria o el titubeo generan una profunda vergüenza que se hace colectiva y en el que el incumplimiento es impensable (Finley 1999: 131-72; Montes 2006; Verger 2009: 66-70).

\section{Conclusiones}

A la hora de comprender los mecanismos de construcción social de las sociedades de la Edad del Hierro en el Cantábrico, la utilización de información antropológica y etnográfica permite establecer marcos comparativos con las evidencias que aportan la Arqueología y las informaciones de los autores grecolatinos. Esto permite, a su vez, desarrollar modelos explicativos de fenómenos esenciales como los expuestos a través de la territorialidad, la reciprocidad y las relaciones vecinales como elementos vertebradores de las redes de relación social (familiar y suprafamiliar) de la Edad del Hierro. Con estos elementos resulta posible comprender la evolución social y territorial en estructuras progresivamente más complejas a lo largo de la Edad del Hierro: desde formas de cooperación económico-territorial hasta órganos de gobierno de las etnias. De este modo creemos que resulta posible acceder a los modos de relación y funcionamiento de la gran mayoría de la sociedad, lo que explica mucho mejor el surgimiento y el papel representado por las élites, en una tendencia inversa a lo que es habitual.

No obstante, estas conclusiones deben ser contrastadas y aplicadas en otras áreas y a distintas escalas territoriales, principalmente de tipo micro y meso, a escala comarcal y regional. Pero creo que, en general, pueden servir como modelo para otras áreas de occidente de Europa con sociedades que, en el mismo ámbito cultural, poseen similares proyecciones político-territoriales, especialmente en las áreas montañosas de Europa.

\section{REFERENCIAS BIBLIOGRÁFICAS}

Alberro, M. (2006): La Feria-Fiesta-Asamblea Óenach de Irlanda y sus posibles paralelos en la antigua Irlanda Céltica. Habis, 37: 159-182.

Almagro-Gorbea, M. (1995): Aproximación paleoetnológica a la Celtiberia meridional: las serranías de Albarracín y Cuenca. III Simposio sobre los Celtíberos. Poblamiento celtibérico. 1991. Zaragoza: 433-446.

Almagro-Gorbea, M. (1999a): Estructura socio-ideológica de los oppida celtibéricos. Pueblos, Lenguas y Escrituras en la Hispania Prerromana. Actas del VII Coloquio sobre Lenguas y Culturas Paleohispánicas. Salamanca: $35-55$.

Almagro-Gorbea, M. (1999b): Dos notas sobre el bronce de Contrebia Belaisca 3 desde la etnohistoria celta. Pueblos, Lenguas y Escrituras en la Hispania Prerromana. Actas del VII Coloquio sobre Lenguas y Culturas Paleohispánicas. Salamanca: 29-34.

Almagro-Gorbea, M (2002): Urbanismo y sociedad en la Hispania Húmeda. En Blas de y Villa 2002: 47-79. 
Almagro-Gorbea, M.; Berrocal-Rangel, L. (1997): Entre íberos y celtas: sobre santuarios comunales urbanos y rituales gentilicios en Hispania. Quaderns de Prehistòria i Arqueeología de Castelló, 18. Espacios y lugares cultuales en el mundo ibérico. Castellón: 567-588.

Álvarez-Sanchís, J.R. (1993): Los Castros de Ávila. Los celtas: Hispania y Europa. M. Almagro-Gorbea, Director. M. Almagro-Gorbea y G. Ruiz-Zapatero Eds. Actas de El Escorial, 4. Editorial Actas. Madrid: 255-284.

Armendériz Martija, J. (2008): De Aldeas a Ciudades. El poblamiento durante el primer milenio a. C. en Navarra. Trabajos de Arqueología Navarra. Monografías Arqueológicas, 2. Institución Príncipe de Viana. Pamplona.

Armendariz Martija, J. (2009): La ordenación del territorio vascón en la Edad del Hierro. Los vascones de las fuentes antiguas. J. Andreu Coord. Edicions Universitat de Barcelona. Barcelona: 303-338.

Asenjo GonzÁlez, M.; Galán, E. (2001): Formas de asentamiento y organización social del espacio. Un modelo de repoblación medieval: el caso de Soria. Un ejemplo de aplicación de fuentes medievales al estudio de la Edad del Bronce. La Edad del Bronce: ¿Primera Edad de Oro de España?. Crítica. Barcelona: 321-344.

Balbín Chamorro, P. (2005): Una propuesta metodológica: utilización de fuentes medievales para el estudio de la Historia Antigua Peninsular. En la España Medieval, 28. Madrid: 355-377.

BARTH, F. (1976a): Introducción. Los grupos étnicos y sus fronteras. La organización social de las diferencias culturales. F. Barth Ed. Fondo de cultura económica. México.

BARTH, F. (1976b): Los Pathanes: su identidad y conservación. Los grupos étnicos y sus fronteras. La organización social de las diferencias culturales. F. Barth Ed. Fondo de cultura económica. México.

Berrocal-Rangel, L. (1992): Los pueblos célticos del suroeste de la Península Ibérica. Complutum, Extra 2. Editorial Complutense. Madrid.

Berrocal-Rangel, L. (1994): El altar prerromano del Castrejón del Capote: ensayo etno-arqueológico de un ritual céltico en el suroeste Peninsular. Excavaciones Arqueológicas en Capote (Beturia Céltica), 2. Universidad Autónoma de Madrid Ed. Madrid.

Berrocal-Rangel, L. (2004a): Banquetes y rituales colectivos en el suroeste Peninsular. Cuadernos de Prehistoria y Arqueología, 30: 105-120.

Berrocal-Rangel, L. (2004b): La defensa de la comunidad: sobre las funciones emblemáticas de las murallas protohistóricas en la Península Ibérica. Gladius, XXIV: 27-98.

Berrocal-Rangel, L., Martínez Seco, P.; Ruiz Triviño, C. (2002): El Castiellu de Llagú. Un Castro Astur en los orígenes de Oviedo. Bibliotheca Archaeologica Hispana, 13. Madrid.

Blas de, Cortina, M.A.; Villa Valdés A. (2002): Los poblados fortificados del noroeste de la Península Ibérica: Formación y desarrollo de la Cultura Castreña. M.A. de Blas Cortina y A. Villa Valdés Eds. Navia.

Blasco Bosqued, M.C. (2001): El poblamiento en las cuencas de los ríos Duero y Tajo durante la Edad del Hierro. Entre celtas e Íberos. Las poblaciones Protohistóricas de las Galias e Hispania. L. Berrocal-Rangel y P. Gardes Eds. Bibliotheca Archaeologica Hispana, 8. Madrid: 201-212.

Braudel, F. (2002): Las ambiciones de la Historia. Crítica. Barcelona.

Brunaux, J.-L. (2004): Guerre et religion en Gaule. Essai d'anthropologie celtique. Editions Errance. Paris.

Brunaux, J.-L. (2008): Les Gaulois. Belles Lettres. Paris.

Burillo Mozota, F. (2007): Los celtíberos. Etnias y estados. (Nueva edición corregida y aumentada). Col. Crítica Arqueología. Grijalbo Mondadori. Barcelona.

Burillo Mozota, F. (2011): Oppida y "ciudades estado" celtibéricos. Aldeas y ciudades en el Primer milenio a.C. La Meseta norte y los orígenes del urbanismo. J. Álvarez Sánchís, A. Jimeno Martínez y G. Ruiz Zapatero Eds. Complutum, 22, 2: 277-295.

CABAl, C. (1992): Las Tradiciones Populares Asturianas II. La Familia la Vivienda y Oficios Primitivos. Anaquel Cultural Asturiano, 16. Oviedo.

Caerols, J.J. (2006): Comentarios a la Guerra de las Galias. C.J. César. Clásicos de Grecia y Roma, 8254. Edición de J.J. Caerols. Alianza Editorial. Madrid.

Camino Mayor, J. (1995): Los Castros marítimos en Asturias. Fuentes y Estudios de Historia de Asturias. Oviedo.

CAmino Mayor, J. (2002): Algunos comentarios sobre las pautas territoriales y sociales de los castros del norte de Asturias. En Blas de y Villa 2002: 139-157.

Camino Mayor, J. (2003): Los castros de la ría de Villaviciosa: contribución a la interpretación de la Edad del Hierro en Asturias. Trabajos de Prehistoria, 60, 1: 159-171.

Camino Mayor, J., Artime Fernández, F.J., Gachs Sánchez, H.M.; García Cosío, X.F. (1997): Estudios del 
Poblamiento Prerromano de la Ría de Villaviciosa. Cuadernos Cubera, 9. Villaviciosa.

Camino Mayor, J.; Viniegra Pacheco, Y. (1999): El horizonte cronológico y cultural de la Edad del Hierro en Asturias. El caso de la Ría de Villaviciosa. II Congreso de Arqueología Penínsular. Primer Milenio y Metodología, III. Alcalá de Henares: 239-248.

Camino Mayor, J., Estrada García, R.; Viniegra Pacheco, Y. (2005): La Carisa. Ástures y Romanos frente a frente. Caja Astur Ed. Oviedo.

Carballo Arceo, L.X. (1990): Los castros de la cuenca media del río Ulla y sus relaciones con el medio físico. Trabajos de Prehistoria, 47, 1: 161-199.

Caro Baroja, J. (1940): Los pueblos del Norte de la Península Ibérica. Análisis histórico-cultural. Consejo Superior de Investigaciones Científicas (CSIC). Madrid.

Caro Baroja, J. (1970): Organización social de los pueblos del norte de la Península Ibérica en la Antigüedad. Legio VII Gemina. León, 1968. León: 11-62.

Caro Baroja, J. (1977): Los Pueblos del Norte. Editorial Txertoa. San Sebastián.

Castiella Rodríguez, A. (1977): La Edad del Hierro en Navarra y Rioja. Excavaciones en Navarra, VII. Pamplona.

Castiella Rodríguez, A. (1993): De la Protohistoria Navarra: la Edad del Hierro. Cuadernos de Arqueología de la Universidad de Navarra, 1: 121-175.

Castiella Rodríguez, A. (1995a): En los albores de la Historia. La Edad del Hierro. Cuadernos de Arqueología de la Universidad de Navarra., 3: 185-230.

Castiella Rodríguez, A. (1995b): Consideraciones sobre la Segunda Edad del Hierro en Navarra. Actas del XXI Congreso Nacional de Arqueología, 1. Vigo. 99-108.

Castiella Rodríguez, A. (1999): Análisis ocupacional de la Cuenca de Pamplona durante el periodo Protohistórico de la Edad del Hierro. Revista de Guimarães, I: 321-331.

Castiella Rodríguez, A. (2004): Peculiaridades del poblamiento prerromano en territorio vascón: Navarra. Cuadernos de Arqueología de la Universidad de Navarra., 12: 177-230.

Castiella, A., Sesma, J., García, M.L., García, J., Prieto, J.J., Faro, J.A.; García, D. (1999a): Poblamiento y territorialidad en la Cuenca de Pamplona: una visión arqueológica. Cuadernos de Arqueología de la Universidad de Navarra., 7, I. Pamplona.

Castiella, A., Sesma, J., García, M.L., García, J., Prieto, J.J., Faro, J.A.; García, D. (1999b): Poblamiento y territorialidad en la Cuenca de Pamplona: una visión arqueológica. Cuadernos de Arqueología de la Universidad de Navarra., 7, II. Pamplona.

Celis SÁnchez, J. (2002): El Bronce Final y la Primera Edad del Hierro en el noroeste de la Meseta. En Blas de y Villa 2002: 97-126.

Collis, J. (2007): The polities of Gaul, Britain, and Ireland in the Late Iron Age. C. Haselgrove u. T. Moore (Coords.), The Later Iron Age in Britain and Beyond. Oxbow Books, Oxford: 523-528.

Dantin Cereceda, J. (1942): Regiones Naturales de España. Tomo I. CSIC. Madrid.

Dincauze, D.F. (2000): Enviromental Archaeology. Principles and practice. Cambridge University Press. Cambridge.

Dyson-Hudson, R.; Alden Smith, E. (1983): Terrotorialidad humana: una reconsideración ecológica. Cultura y Ecología en las Sociedades Primitivas. Selección de M.J. Buxó Rey. Temas de Antropología. Editorial Mitre. Barcelona. 151-185.

EspinA, A. (2005): Darwinismo social: de Spencer a Bagehot. Reis, 110: 175-187.

Fanjul Peraza, A. (2005): Los castros de Asturias, una revisión territorial y funcional. Treverga.

Fanjul Peraza, A.; Menéndez Bueyes, L.R. (2004): El complejo castreño de los Astures Trasmontanos. Acta Salmanticensia. Estudios Históricos y Geográficos, 128. Salamanca.

Fernández Acebo, V., Martínez Velasco, A.; Serna Gancedo, M.L. (2010): Los poblados fortificados de la Edad del Hierro y las estructuras campamentales romanas en Cantabria: Reflexiones sobre el poblamiento, el reparto geográfico y la configuración. Castros y Castra en Cantabria. Fortificaciones desde los origenes de la Edad del Hierro a las Guerras con Roma. A. Serna; A. Martínez; V. Fernández, Coord. Santander: 589-641.

Fernández Benítez, V, Fernández García, J.A., Fernández García; X., García Martínez, A., López Álvarez, J. Martínez Lorenzo, L., Muñoz Fuente, J.A., Prieto Vergara, M.A., Rodríguez Rodríguez, R., Suarez López, J. Suarez Rodríguez, M.; Villa Gutiérrez, J. (2002): Trabajar para comer. Producción y alimentación en la Asturies tradicional. Documentación General. Gijón. 
Fernández-Götz, M.A. (2008): La construcción arqueológica de la etnicidad. Serie Keltia, 42, Editorial Toxosoutos. Coruña.

Fernández-Götz, M.A. (2011a): Niveles sociopolíticos y órganos de gobierno en la Galia de finales de la Protohistoria, Habis, 42: 7-26.

Fernández-Götz, M.A. (2011b): Cultos, ferias y Asambleas: los santuarios Protohistóricos del Rin Medio-Mosela como espacios de Agregación. Palaeohispánica, 11: 127-154.

FichtL, S. (1994): Les Gaulois du nord de la Gaule (150- 20 av. J.C.). Collection des Hesperides. Éd. Errance, Paris.

FichtL: S. (2004): Les peuples gaulois. IIIe-Ier siècles av. J.-C. Collection des Hesperides. Éd. Errance. Paris.

Fichtl, S. (2005): La Ville Celtique. Les oppida de 150 av. J.-C.à 15 ap. J.-C. Deuxième édition revue et augmentée. Éd. Errance, Paris.

Fichtl, S. (2012a): Les Peuples Gaulois. Édition revue et augmentée. Éd. Errance, Paris.

FichtL, S. (2012b): Les premières viles de Gaule. Les temps des oppida celtiques. Collection Archéologie Vivante. Editions Archéologie Nouvelle. Lacapelle-Marival.

Fidalgo Santamariña, J.A. (1984): Notas sobre los "trabajos colectivos" de una parroquia rural. I Coloquio de Antropoloxia de Galicia. Ediciones do Castro. La Coruña: 61-68.

Finley, M.I. (1999): El Mundo de Odiseo. Breviarios del Fondo de Cultura Económica, 158. Fondo de Cultura Económica. Madrid.

García-Quintela, M.V. (2002): La organización socio-política de los populi del noroeste de la Península Ibérica. Un estudio de antropología política histórica comparada. Traballos de Arqueoloxia e Patrimonio, 28: 16-122.

García Quintela, M.V.; Criado Boado, F.; González García, F.J.; Parcero Oubiña, C.; Santos Estévez, M. (2003): Souveraineté et sanctuaires dans lÉspagne celtique. Etudes Comparees D'Historie et D'Archeologie. Memoires de la Societe Belge d'Etudes Celtiques, 17. Bruselas: 75-90.

García-Quintela, M.V.; Santos Estévez M. (2008): Santuarios de la Galicia Céltica. Arqueología del Paisaje y religiones comparadas en la Edad del Hierro. Lecturas Serie Historia Antigua. Abada Editores. Madrid.

Gil Zubillaga, E. (1993): El poblado de Atxa (Vitoria), un ejemplo de asentamiento de la II Edad del Hierro con aculturación celtibérica en el valle del Zadorra. Bajo Aragón Prehistoria. Vols. IX-X, 1992-93 Segundos Encuentros de Prehistoria Aragonesa. Zaragoza: 167-174.

Gil Zubillaga, E. (1995): Atxa: Memorias de las excavaciones arqueológicas 1982-1988. Departamento de Cultura, Diputación Foral de Álava. Vitoria.

Gil Zubillaga, E.; Filloy Nieva, I. (1986): Organización del Microespacio en el yacimiento de Atxa (Vitoria). II Edad del Hierro/Romanización. Avance a su estudio. Arqueología Espacial (Coloquio sobre el Microespacio), 4. Seminario de Arqueología y Etnología Turolense (SAET). Colegio Universitario de Teruel. Teruel.

Giobellina Brumana, F. (2010): El don del ensayo. Ensayo sobre los Dones. Forma y función del intercambio en las Sociedades Arcaicas. Edición de F. Giobellina Brimana. Col. Conocimiento. Ed. Katz. Buenos Aires. 7-60.

Godelier, M. (1999): The enigma of the gift. Polity Press \& Blackwell Publishers. Cambridge.

Godelier, M. (2000): Acerca de las cosas que se dan, de las cosas que se venden y de las que no hay que vender ni dar sino que hay que guardar. Una reevaluación crítica del ensayo sobre el don de Marcel Mauss. Hispania: Revista española de historia, 60, 204: 11-26

Gómez Pellón, E. (1994): Vida tradicional y proceso de cambio en un valle del oriente asturiano. Principado de Asturias. Oviedo.

Gómez Pellón, E. (2005): La buena vecindad y la ayuda mutua en el medio rural de Cantabria. II Encuentro de Historia de Cantabria, Vol. 2. M.R. González, J.A. Solorzano Coord. Santander. 895-927.

GonzÁlez y Fernández Vallés, J.M. (1966): Catalogación de los castros asturianos. Archivum, XXVI: $255-291$.

GonzÁlez y Fernández Vallés, J.M. (1976): Antiguos pobladores de Asturias protohistórica. Colección Popular Asturiana, 3. Ayalga Ediciones. Oviedo.

González y Fernández Vallés, J.M. (1978): Asturias Protohistórica. Historia de Asturias, 2. Ayalga Ediciones. Gijón.

GonzÁlez Rodríguez, M.C. (1986): Las unidades organizativas indígenas del área indoeuropea de Hispania. Veleia, Anejo, 2. Vitoria.

González Ruibal, A. (2007): Galaicos. Poder y comunidad en el noroeste de la Península Ibérica (1200 a. C.-50 d.C.). Tomo I y II. Brigantium, 18 y 19 (2006-2007). A Coruña. 
Hernández Pacheco, E. (1934): Síntesis fisiográfica y geológica de España. Trabajos del Museo Nacional de Ciencias Naturales. Geológica, 38. Madrid.

Homoвono, J.I. (1991): Ámbitos culturales, sociabilidad y grupo doméstico en el País Vasco. Antropología de los Pueblos del Norte de España. Universidad Complutense de Madrid, Universidad de Cantabria. Madrid: 83-114.

JAMES, S. (2005): El mundo de los celtas. Editorial Blume. Barcelona.

Jullian, C. (1901): Notes gallo-romaines IX, À propos des "pagi" galulois avant la conquête romaine. Revue des Études Anciennes, 3: 77-97.

Kruta, V. (2000): Les Celtes. Histoire et Dictionaire. Des origines à la romanisation et au christianisme. Bouquins. Editions Robert Laffont. Paris.

Llanos Ortiz de Landaluze, A. (1990a): La Edad del Hierro y sus precedentes en Álava y Navarra. Munibe (Antropología-Arkeología), 42. Homenaje a D. José Miguel Barandiaran. San Sebastián: 167-179.

Llanos Ortiz de Landaluze, A. (1990b). Necrópolis del Alto Ebro. II Simposio sobre los Celtíberos. Necrópolis Celtibéricas. F. Burillo Ed. Institución Fernando el Católico. Zaragoza: 137-147.

Llanos Ortiz de Landaluze, A. (1992): Conformación de las étnias prerromanas en Álava, Bizkaia y Guipúzkoa. Complutum, 2-3 (1992). Paleoetnología de la Península Ibérica. M. Almagro-Gorbea y G. Ruiz Zapatero Eds. Madrid: 431-447.

Llanos Ortiz de Landaluze, A. (1995): El Poblamiento celtibérico, en el alto valle del Ebro. III Simposio sobre Los Celtíberos. Poblamiento Celtibérico. F. Burillo Coord. Institución Fernando el Católico (CSIC). Zaragoza: 289-328.

Llanos Ortiz de Landaluze, A. (1997). La Edad del Hierro en Vasconia. Isturiz. Cuadernos de Prehistoria y Arqueología, 7: 37-45.

Llanos, A., Armendáriz, J., Castiella, A., Peñalver, X., Sáenz, P.; Unzueta, M. (2009): La Edad del Hierro en el Cantábrico Oriental y su entorno. Medio Siglo de Arqueología en el Cantábrico Oriental y su entorno. Actas del Congreso Internacional. A. Llanos Ortiz de Landaluce Coord. Vitoria: 201-344.

Marco Simón, F. (1993): La religiosidad en la Céltíca hispana. Los Celtas: Hispania y Europa. M. Martín Almagro Gorbea y G. Ruiz-Zapatero Eds. Actas de El Escorial, 4. Editorial Actas. Madrid. 477-512.

Marcos García, M.A. (1987): Estructuras defensivas en los castros cántabros de la cabecera del Ebro. Zephyrus, Revista de Prehistoria y Arqueología, XXXIX-XL Actas del Coloquio Internacional sobre la Edad del Hierro en la Meseta Norte. Salamanca: 479-483.

Mauss, M. (1971): Ensayo sobre los Dones. Razón y forma del cambio en las Sociedades Primitivas. Sociología y Antropología. Colección de Ciencias Sociales, Serie de Sociología. Editorial Tecnos. Madrid: 153-263.

Mauss, M. (2010): Ensayo sobre los Dones. Forma y función del intercambio en las Sociedades Arcaicas. Edición de F. Giobellina Brimana. Col. Conocimiento. Ed. Katz. Buenos Aires.

Maya GonzÁlez, J.L. (1983): La cultura castreña asturiana: de los orígenes a la romanización. Indigenismo y romanización en el Conventus Asturum. Universidad de Oviedo. Madrid-Oviedo: 11-44.

Maya González, J.L. (1984): Hábitat y cronología de la cultura castreña en Asturias. Portugalia, IV-V: $175-198$.

Maya GonzÁlez, J.L. (1988): La cultura material de los Castros Asturianos. Estudios de la Antigüedad. Monográfico, 4/5, 1987-1988. Barcelona.

Maya GonzÁlez, J.L. (2000): Castros Asturianos: cronología y atribución étnica. I Seminariu d'Estudios Astruianos de la Fundación Belenos. Cuestiones d'Antorpoloxía y Arqueoloxía. Homenaje al Profesor José Luis Maya González. Fundación Belenos Ed. Oviedo: 21-39.

Maya González, J.L.; Cuesta Toribio, F. (2001): El Castro de la Campa Torres. Periodo Prerromano. Serie Patrimonio, 6. VTP. Gijón.

Méndez, R.; Molinero, F. (1994): Espacios y Sociedades, Introducción a la geografía regional del mundo. Ariel Geografía. Editorial Ariel S.A. Barcelona.

Montes Miralles, M.Y. (2006): El miedo al desorden: estrategias de recuperación del equilibrio social en el mito iliádico. Gerión Vol. 24: 119-141.

Moreno Feliu, P. (2011): El bosque de las gracias y sus pasatiempos. Raíces de la Antropología Económica. Ed. Trotta. Madrid.

Moore, T. (2011): Destribalizing the later prehistoric past: Concepts of tribes in Iron Age and Roman studies. Journal of social Archaeology, 11, 3: 334-360. 
Moya-Maleno, P.R. (2008): Etnografía y Etnohistoria aplicadas a la Hispania Céltica. Actas de las I Jornadas de Jóvenes en Investigación Arqueológica: dialogando con la cultura material (JIA 2008). Vol. I. OrJIA Coords., Eds. Cersa. Madrid: 215-222.

Moya-Maleno, P.R. (2013): Paleoetnología de la Hispania Céltica: Etnoarqueología, Etnohistoria y Folklore como fuentes de la Protohistoria. Tesis Doctoral. Universidad Complutense. Madrid.

Muñiz Coello, J. (1994): Pueblos y Comunidades Celtas e Ibéricas. Un análisis de los términos literarios. Hispania Antiqua, XVIII: 77-89.

Murcia Navarro, E. (1980): Estructuración regional de la España Atlántica. La región y la Geografía Española. Coord. J. García Fernández. Jornadas sobre la Región y la Geografía Española, 1979. Valladolid: 179-190.

Osteed, M. (2002): The question of the gift. Essays across disciplines. M. Osteed Ed. Routledge. London-New York.

Parcero Oubiña, C. (2000): Tres para dos. Las formas de poblamiento en la Edad del Hierro del noroeste ibérico. Trabajos de Prehistoria, Vol.57, 1: 75-95.

Parcero Oubiña, C. (2002): La construcción del paisaje social en la Edad del Hierro en el Noroeste Ibérico. Ortegalia. Monografías de Arqueoloxia, Historia e Patrimonio, 1. Ortigueira.

Peñalver Iribarren, X. (2001a): El Bronce Final y la Edad del Hierro en la Euskal Herria Atlántica: Cromlechs y Castros. Complutum, Vol. 12: 51-71.

Peñalver Iribarren, X. (2001b): El Hábitat en la vertiente atlántica de Euskal Herría. El Bronce Final y la Edad del Hierro. Kobie, serie Anejos, 3. Bilbao.

Peñalver, X y San José, S. (2003): Burdin Aroko herri harresituak Guipúzcoan. Bertan, 20. Diputación Foral de Guipúzcoa. San Sebastián.

Peñalver, X.; San José, S. (2011): Burdin Aroa Gipuzkoan/La Edad del Hierro en Gipuzkoa. Arkeologia 0.3. Gipuzkoako Foru Aldundia. San Sebastian.

Peralta Labrador, E. (2003): Los Cántabros antes de Roma, 2a Edición Corregida y Ampliada. Bibliotheca Archaeológica Hispana, Vol. 5. Real Academia de la Historia Ed. Madrid.

Pereira Menaut, G. (1982): Los castella y las comunidades de Gallaecia. Zephyrus, XXXIV-XXXV: $249-268$.

Pereira Menaut, G. (1983): Los castella y las comunidades de Gallaecia. Actas del II Seminario de Arqueología del Noroeste. Seminario de Arqueología del Noroeste. Ministerio de Cultura, Dirección General de Bellas Artes y Archivos. Madrid: 167-192.

Peyre, Ch. (1996): Prologue Monnayages et Peuples gaulois du Nord-Ouest. L.P. Delestrée. Maison FlorangeClaude Burgan Eds. Paris: 5-8.

PolanYi, K. (1987): La gran transformación. Ediciones de La Piqueta. Ediciones Endymion. Madrid.

Rivas Rivas, A.M. (1991a): Representaciones colectivas y maneras de ser del cántabro. Antropología de los pueblos del Norte. Un. Complutense de Madrid y Un. de Cantabria Eds. Madrid: 63-82.

Rivas Rivas, A.M. (1991b): Antropología Social de Cantabria. Universidad de Cantabria. Santander.

Rodríguez Colmenero (2001): Los castella de Susarros y Gigurros en el Noroeste Hispánico y sus primeras relaciones con Roma a través del bronce de Bembibre y otros documentos de reciente aparición. El bronce de Bembibre. Un edicto del Emperador Augusto del año 15 a. C. Museo de León. Valladolid: 67-96.

Roymans, N. (1990): Tribal societies in Northern Gaul. An Anthropological Perspective. Universiteit van Amsterdam, Albert Egges van Giffen Instituut voor Prae- en Protohistorie. Amsterdam.

Ruiz-Zapatero, G. (1995): El sustrato de la Celtiberia Citerior. El problema de las invasiones. III Simposio sobre Los Celtíberos. Poblamiento Celtibérico. F. Burillo Coord. Institución Fernando el Católico (CSIC). Zaragoza: 25-40.

Ruiz-Zapatero, G.; Álvarez-Sanchís, J. (1999): Ulaca, la Pompeya Vetona. Revista de Arqueología, 20, 216 : 36-47.

Sacristán de Lama, J.D. (2011): El urbanismo vacceo. Aldeas y ciudades en el Primer milenio a.C. La Meseta norte y los orígenes del urbanismo. J. Álvarez Sánchís, A. Jimeno Martínez y G. Ruiz Zapatero Eds. Complutum Vol. 22, 2: 185-222.

Sacristán de Lama, J.D., San Miguel Maté, L.C., Barro Martin, J.; Celis Sanchez, J. (1995): El poblamiento de época celtibérica en la cuenca media del Duero. III Simposio sobre Los Celtíberos. Poblamiento Celtibérico. F. Burillo Mozota Coord. Zaragoza: 337-367.

San Miguel Maté, L.C. (1995): Civitas y secundarización de la producción, ¿Las dos claves de interpretación del 
poblamiento vacceo? III Simposio sobre Los Celtiberos. Poblamiento Celtibérico, 1991. Institución Fernando el Católico (CSIC) y Diputación de Zaragoza Eds. Zaragoza: 373-380.

Santos Yanguas, N. (1985): Comunidades Indígenas y administración romana en el noroeste hispánico. Servicio Editorial Universidad del País Vasco. Bilbao.

Serna Gancedo, M.L., Martínez Velasco, A.; Fernández Acebo, V. (2010): Castros y Castra en Cantabria. Fortificaciones desde los orígenes de la Edad del Hierro a las Guerras con Roma. Catálogo, revisión y puesta al día A. Serna; A. Martínez; V. Fernández, Coord. Acanto. Santander.

Shalins, M. (1983): Economía de la Edad de Piedra. Akal Universitaria. Antropología, 61. Akal. Torrejón de Ardoz.

Solana Sáinz, J.M. (1993): Centros urbanos y administración del territorio en la Submeseta septentrional de Hispania (s. I-II d. C.). Hispania Antiqua, XVII:159-182.

SYKes, K. (2005): Arguing with anthropology: an introduction to critical theories of the gift. K. Sykes Ed. Routledge. Oxon-New York.

TÁcito, P.C. (1999): Vida de Julio Agrícola. Germania. Diálogo de los oradores. Edición de B. Alarcón, Martínez. Akal/Clásica, 52. Clásicos Latinos. Madrid.

Torres-Martínez, J.F.K. (2003): La Economía de los Celtas de la Hispania Atlántica. Vol. I Agricultura, ganadería y recursos naturales. Serie Keltia, 21, Editorial Toxosoutos. Coruña.

Torres-Martínez, J.F.K. (2005): La Economía de los Celtas de la Hispania Atlántica, II. Economía, territorio y Sociedad. Serie Keltia, 28, Editorial Toxosoutos. Coruña.

Torres-Martínez J.F.K. (2006): La Etnohistoria aplicada al estudio de las sociedades de la Edad del Hierro Final del norte de la Península Ibérica. Etnoarqueología de la Prehistoria, más allá de la analogía. Treballs d'Etnoarqueología Vol. 6. Madrid: 285-295.

Torres-Martínez, J.F.K. (2010): El Medio ambiente antiguo, la construcción del territorio y la obtención de recursos en la Edad del Hierro de Cantabria. Castros y Castra en Cantabria. Fortificaciones desde los origenes de la Edad del Hierro a las Guerras con Roma. A. Serna; A. Martínez; V. Fernández, Coord. Santander: 74109.

Torres-Martínez, J.F.K. (2011): El Cantábrico en la Edad del Hierro. Medioambiente, Economía, Territorio y Sociedad. Bibliotheca Archaeologica Hispana, 35. Madrid.

Torres-Martínez, J.F.K.; SAgardoy Fidalgo, T. (2004): Economía ganadera en la zona cantábrica en el final de la Edad del Hierro. Kobie, serie Anejos, 6, 1. Homenaje al Profesor Dr. Juan Mà . Apellániz.. Bilbao: 315-332.

Torres-Martínez J.F.K.; SAgardoy Fidalgo, T. (2006): La Etnoarqueología en el norte de la Península Ibérica y el estudio de las sociedades Protohistóricas. Etnoarqueología de la Prehistoria, más allá de la analogía. Treballs d’Etnoarqueología Vol. 6. Madrid: 95-108.

VALDÉs, L. (2006): El santuario protohistórico de Gastiburu (siglos IV al I a.C.) y el calendario estacional (Arratzu, Bizkaia). Munibe (Antropología, Arqueología), 57, 2. Homenaje a Jesús Altuna. San Sebastián: 333-343.

VAldÉs, L. (2009a): Gastiburu. El santuario vasco de la Edad del Hierro. Texto. Bibliotheca Archaeologica Hispana, 29. Madrid.

VAldés, L. (2009b): Gastiburu. El santuario vasco de la Edad del Hierro. Imágenes. Bibliotheca Archaeologica Hispana, 29. Madrid.

Valdés, L.; PuJANA, I (2003): El santuario protohistórico de Gastiburu y el calendario estacional (siglos IV al I a. C.). Bolskan, 19. Ponencias y Comunicaciones presentadas en el XXVII Congreso Nacional de Arqueología. Huesca: 249-254.

VALDÉS DEL TORO, R. (2004): Ecología, trabajo, fiestas y dieta en un concejo del occidente Astur (1960). ¿Bótoche unha mao? La evolución de las relaciones de reciprocidad campesinas en Tapia de Casariego (Asturias) (1960-2000). R. Valdés del Toro, R.; E. Lorenzi Fernández. Fuentes para el Estudios de la Antropología Asturiana, 9. Gijón.

Valdés del Toro, R.; LoRenzi Fernández, E. (2004): ¿Bótoche unha mao? La evolución de las relaciones de reciprocidad campesinas en Tapia de Casariego (Asturias) (1960-2000). Fuentes para el Estudio de la Antropología Asturiana, 9. Gijón.

Valle Gómez, M.A.; Serna Gancedo, A. (2003): El castro de Castillnegro y otros asentamientos de la Edad del Hierro en el entorno de la Bahía de Santander. La Arqueología de la Bahía de Santander. Tomo I. C. Fernández Ibáñez y J. Ruiz Cobo Eds. Santander: 353-390.

Van Gennep, A. (1986): Los ritos de paso. Colección Ensayistas, 226. Taurus Ediciones. Madrid. 
Villa Valdés, A. (2000): Aportaciones al estudio de la evolución del espacio urbano castreño en el occidente de Asturias (siglos IV a. C.-II d. C.). Actas do $3^{\circ}$ Congresso de Arqueología Penínsular, Vila Real Portugal, Setembro de 1999. Proto-Historia da Península Ibérica, Vol. V. Coordinador General V. Oliveira Jorge. ADECAP. Porto: 507-521.

Villa Valdés, A. (2002a): Periodización y registro arqueológico en los castros del occidente de Asturias. En de Blas y Villa 2002: 159-188.

Villa Valdés, A. (2002b): Sobre la secuencia cronoestatigráfica de los castros asturianos (ss. VIIIa. C.-II d. C.). Trabajos de Prehistoria, 59, 2: 149-162.

Villa Valdés, A. (2007): El Chao San Martín (Grandas de Salime, Asturias) y el paisaje fortificado en la Asturias Protohistórica. Paisajes Fortificados de la Edad del Hierro. Las murallas protohistóricas de la meseta y la vertiente atlántica en su contexto europeo. L. Berrocal-Rangel y P. Moret Eds. Bibliotheca Archaeologica Hispana Vol. 28. Real Academia de la Historia y Casa de Velázquez. Madrid: 191-212.

Verger, S. (2009): Société, Politique et religion en Gaule avant la Conquête. Éléments pour une étude anthropologique. Pallas, 80: 61-82.

Wolf, E. (1975): Los Campesinos. Nueva Colección Labor, Sociología y Economía, 126. Editorial Labor. Barcelona. 